\title{
Guanidine : A Highly Efficient Stabilizer in Atmospheric New-Particle Formation
}

\section{Myllys, Nanna}

2018-05-24

Myllys , N , Ponkkonen , T , Passananti , M , Elm , J , Vehkamäki , H \& Olenius , T 2018 , ' Guanidine : A Highly Efficient Stabilizer in Atmospheric New-Particle Formation ' , Journal of pÿPhysical Chemistry A , vol. 122 , no. 20 , pp. 47174729 . https://doi.org/10.1021/acs.jpca.8b02507

http://hdl.handle.net/10138/256026

https://doi.org/10.1021/acs.jpca.8b02507

unspecified

publishedVersion

Downloaded from Helda, University of Helsinki institutional repository.

This is an electronic reprint of the original article.

This reprint may differ from the original in pagination and typographic detail.

Please cite the original version. 


\title{
Guanidine: A Highly Efficient Stabilizer in Atmospheric New-Particle Formation
}

\author{
Nanna Myllys, ${ }^{*} \dagger \odot$ Tuomo Ponkkonen, ${ }^{\dagger}$ Monica Passananti, ${ }^{\dagger}$ Jonas Elm, $^{\dagger}{ }^{\dagger}$ Hanna Vehkamäki, ${ }^{\dagger}$ \\ and Tinja Olenius $*, \S, \S$ \\ ${ }^{\dagger}$ Institute for Atmospheric and Earth System Research/Physics, University of Helsinki, P.O. Box 64, 00014 Helsinki, Finland \\ ${ }^{\ddagger}$ Department of Chemistry and iClimate, Aarhus University, Langelandsgade 140, DK-8000 Aarhus, Denmark \\ ${ }^{\S}$ Department of Environmental Science and Analytical Chemistry and Bolin Centre for Climate Research, Stockholm University, \\ Svante Arrhenius väg 8, SE-114 18 Stockholm, Sweden
}

\section{Supporting Information}

ABSTRACT: The role of a strong organobase, guanidine, in sulfuric aciddriven new-particle formation is studied using state-of-the-art quantum chemical methods and molecular cluster formation simulations. Cluster formation mechanisms at the molecular level are resolved, and theoretical results on cluster stability are confirmed with mass spectrometer measurements. Newparticle formation from guanidine and sulfuric acid molecules occurs without thermodynamic barriers under studied conditions, and clusters are growing close to a 1:1 composition of acid and base. Evaporation rates of the most stable clusters are extremely low, which can be explained by the proton transfers and symmetrical cluster structures. We compare the ability of guanidine and dimethylamine to enhance sulfuric acid-driven particle formation and show that more than 2000-fold concentration of dimethylamine is needed to yield as efficient particle formation as in the case of guanidine. At similar conditions,
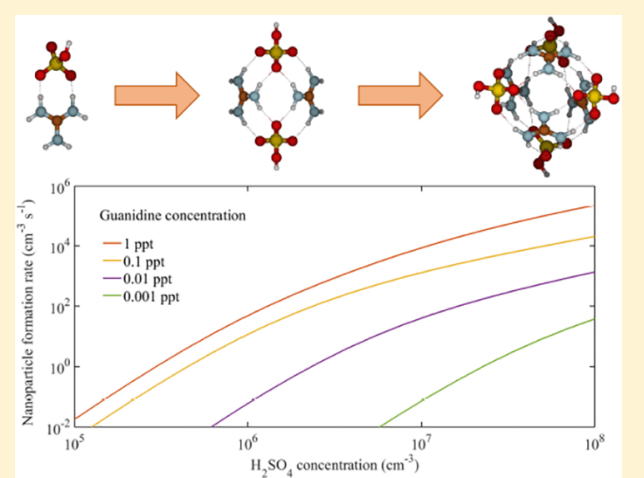
guanidine yields 8 orders of magnitude higher particle formation rates compared to dimethylamine. Highly basic compounds such as guanidine may explain experimentally observed particle formation events at low precursor vapor concentrations, whereas less basic and more abundant bases such as ammonia and amines are likely to explain measurements at high concentrations.

\section{INTRODUCTION}

The formation of atmospheric aerosol particles from vapors is a complex phenomenon, and the exact molecular-level mechanisms and participating compounds in different atmospheric environments remain highly uncertain. ${ }^{1,2}$ Aerosol particles significantly affect human health, climate change, and visibility. ${ }^{3}$ New-particle formation (NPF) occurs via gas-to-particle conversion, where sulfuric acid has been shown to be a key player in many locations. ${ }^{4}$ However, sulfuric acid alone cannot drive atmospheric molecular cluster formation due to its low concentration, and some stabilizing compounds are needed to explain observed NPF events. The most probable candidates include ammonia, amines, ions, and nonbasic organic compounds. $^{5-12}$ Bases are important species for stabilizing sulfuric acid clusters by proton transfer reactions. Ammonia has been extensively studied since it is the most abundant base in the atmosphere. A major source of ammonia is agriculture, and other sources include industries, vehicular exhausts, vegetation, and oceans. ${ }^{13}$ However, ammonia-sulfuric acid clustering alone cannot explain measured NPF rates, and thus a lot of research has focused on the role of amines, which are generally stronger bases compared to ammonia. ${ }^{14}$ The main sources of amine emissions are industrial processes, animal husbandry, fish processing, and landfills. ${ }^{15}$ Approximately 150 amines have been detected in the atmosphere, with alkylamines being the most common ones. ${ }^{16}$ It has been shown that amines enhance sulfuric acid-driven clustering significantly more strongly than ammonia. ${ }^{17-19}$ For instance, CLOUD chamber experiments at CERN showed that $3 \mathrm{ppt}_{V}$ of dimethylamine is able to increase molecular cluster formation rates by more than 1000-fold compared to $250 \mathrm{ppt}_{V}$ of ammonia. ${ }^{20}$ This indicates that not only the atmospheric abundance but also the basicity of the participating base together with its ability to form hydrogen bonds are important when estimating the potential to form stable clusters with sulfuric acid. ${ }^{21}$

Recent studies have shown that diamines are able to enhance cluster formation even more effectively than previously studied monoamines such as dimethylamine. ${ }^{22}$ Flow tube experiments performed by Jen et al. showed that diamines produce 10 times more particles than dimethylamine and 100 times more than methylamine at similar conditions. ${ }^{23}$ Using computational methods, it was recently identified that diamines interact significantly more strongly with sulfuric acid than monoamines such as dimethylamine. ${ }^{24}$ Putrescine was found capable of

Received: March 14, 2018

Revised: April 25, 2018

Published: April 25, 2018 
accepting two protons leading to more strongly bound clusters, as the molecular interactions are shifted from simple hydrogen bonding to stronger electrostatic interactions. This leads to a 6 orders of magnitude increase in the formation rate of stable clusters compared to the case with sulfuric acid and dimethylamine. Clusters consisting of one or two putrescine and up to four sulfuric acid molecules were found to be stable against evaporation, which was further confirmed by electrospray ionization atmospheric pressure interface time-of-fight (ESI-APi-TOF) experiments. These results suggest that diamines or other compounds with a high basicity might have an important role in the initial cluster formation. ${ }^{24}$ On the other hand, more abundant amines with lower basicity may still further participate in the new-particle formation by attaching to the pre-existing stable clusters. Indeed, both experimental and theoretical studies have suggested that mixing of ammonia and amines may significantly affect the sulfuric acid-driven particle formation rates. ${ }^{25-27}$ These findings imply that a wide range of basic species may be required to explain the experimentally observed cluster formation events in different environments.

We study the potential of strong bases to enhance sulfuric acid-driven NPF. In this study we use guanidine $(\mathrm{HN}=$ $\left.\mathrm{C}\left(\mathrm{NH}_{2}\right)_{2}\right)$ as a proxy for strong bases that may be present in the atmosphere and explore the molecular interaction between sulfuric acid and guanidine. Guanidine is a strong organobase with a $\mathrm{pK}_{\mathrm{a}}$ value of 13.6 in water solution, where it is protonated and forms the guanidinium cation $\left(\mathrm{C}\left(\mathrm{NH}_{2}\right)_{3}{ }^{+}\right){ }^{28}$ Guanidine contains one imino group and two amino groups. When the imino group accepts a proton, there are three identical amino groups, and the structure is symmetric and stabilized by resonance. ${ }^{29}$ It should be noted that the amino groups in guanidinium are not as basic as amines, since the carbon atom already carries a positive charge, and therefore guanidine is very unlikely to accept more than one proton. ${ }^{30}$ In the guanidinium electronic structure, six $\pi$-electrons are delocalized over the Y-shaped plane, which makes its structure extraordinarily stable. Symmetry, resonance, and Y-delocalization of guanidinium strongly affect the gas-phase proton affinity of guanidine $(226.9 \mathrm{kcal} / \mathrm{mol})$, which is close to that of triethylamine $(227.3 \mathrm{kcal} / \mathrm{mol}){ }^{31}$ Guanidine can be emitted to the atmosphere from anthropogenic sources such as industry, where it is used in plastic and explosive production. ${ }^{32-34}$ Guanidine has also been found in urine as a normal product of protein metabolism. ${ }^{35}$ Urine contains guanidine as a hydrolysis product of the proteinogenic amino acid arginine, ${ }^{36}$ and large quantities of arginine are annually biosynthesized. ${ }^{37-39}$ In addition, animal husbandry and degrading bacteria-mass might be important sources of guanidine in the atmosphere. ${ }^{40,41}$ The molecular structures of guanidine and guanidinium are shown in Figure 1.

Using high-level quantum chemical methods, we study the thermodynamics of guanidine-sulfuric acid clusters. The interaction between guanidine and sulfuric acid is very strong due to the proton transfer from sulfuric acid to guanidine and the efficient resonance stabilization of the guanidinium ion.

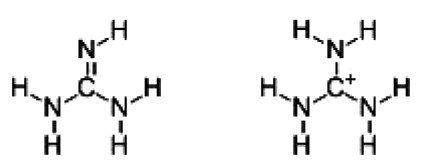

Figure 1. Structures of guanidine (left) and guanidinium ion (right).
Using the Atmospheric Cluster Dynamic Code (ACDC), ${ }^{42}$ we further investigate the cluster kinetics and population dynamics. These methods give a detailed analysis of the cluster stability against evaporation and step-by-step growth pathways, as well as quantities that can be measured or applied in atmospheric science, such as cluster concentrations and formation rates. The theoretical findings are confirmed with laboratory experiments using an ESI-APi-TOF mass spectrometer.

\section{METHODS}

The Gibbs free energies of cluster formation were calculated for guanidine-sulfuric acid clusters containing up to four guanidine and four sulfuric acid molecules. These energies were used to calculate cluster evaporation rate constants, which were applied in dynamic simulations of cluster formation.

2.1. Structure Sampling and Gibbs Free Energies. All geometry optimizations and vibrational frequency calculations were carried out in Gaussian 16. ${ }^{43}$ Single point energy calculations were run using the Orca 4.0.0.2. program. $^{44}$ Thermochemical parameters are calculated using a rigid rotor and harmonic oscillator approximation, and all values are reported in $\mathrm{kcal} / \mathrm{mol}$ at $298.15 \mathrm{~K}$ and $1 \mathrm{~atm}$ unless otherwise stated. It should be noted that the guanidine-sulfuric acid cluster structures are very rigid due to a high number of intermolecular interactions (see section 3.1). Therefore, internal rotations (which might artificially increase the vibrational entropy) are very unlikely, and thus the usage of the rigid rotor approach is in this case well-justified.

We used the following semiempirically guided technique to obtain the minimum energy structures for the guanidinesulfuric acid clusters: ${ }^{45}$

1. In each cluster formation step 1000-2000 randomly oriented cluster structures are created.

2. The structures are initially optimized using the semiempirical parametric method number 6 (PM6). ${ }^{46}$

3. The converged structures are optimized with a density functional theory (DFT) level of M06-2X/6-31+G*. ${ }^{47}$

4. The structures are sorted, characterized by the electronic energy, and different conformations are identified.

5. Conformations within $15 \mathrm{kcal} / \mathrm{mol}$ of the lowest identified conformation are geometry optimized, and frequencies are calculated at the M06-2X/6-31++G** level of theory.

6. The structures are sorted based on the Gibbs free energy, and several (3-10 depending on the system) lowest energy conformations are used to build larger clusters.

The three or four lowest M06-2X/6-31++G** Gibbs free energy conformers from the cluster sampling are optimized, and vibrational frequencies are calculated using the PW91 and $\omega$ B97X-D functionals with the $6-31++G^{* *}$ basis set. ${ }^{47-52}$ This is because different types of functionals involve different sources of errors and uncertainties, and there are no methods to systematically improve the results obtained for a specific functional. In order to eliminate random errors caused by the use of a single functional, we have selected three different types of functionals that have been shown to perform well for atmospheric clusters, and the final results are presented as an average of these functionals. M06-2X is a heavily parametrized hybrid-meta functional, PW91 is a generalized gradient approximation functional, and $\omega \mathrm{B} 97 \mathrm{X}-\mathrm{D}$ is a range-separated hybrid functional with empirical dispersion corrections. These functionals have been shown to perform well for kinetics, 
thermodynamics, and noncovalent interactions. ${ }^{53-55} \mathrm{~A}$ very tight optimization criterion is used in all the DFT calculations. We use a small $6-31++\mathrm{G}^{* *}$ basis, which has been confirmed to be sufficient for geometry optimization and thermochemistry of atmospheric molecular clusters. ${ }^{56,57}$ The thermal contribution to the Gibbs free energy also contains the vibrational zero point energy, and it is calculated as follows:

$$
\Delta G_{\text {Therm }}=G_{\text {Therm,cluster }}-\sum_{i} G_{\text {Therm,monomer }, i}
$$

It has been shown that DFT yields a large variation in binding energies, and thus electronic energy corrections with a higher level correlated method are needed. ${ }^{58}$ We have calculated the electronic energy corrections on top of the DFT geometries using a domain-based local pair natural orbital coupled cluster method (DLPNO-CCSD $(\mathrm{T})$, referred to simply as DLPNO $)^{59-61}$ with an aug-cc-pVTZ basis set ${ }^{62,63}$ and a tight pair natural orbital criterion (TightPNO). A TightPNO criterion is recommended for noncovalently bound systems. ${ }^{64}$ DLPNO has been shown to yield results close to the canonical coupled cluster level of theory with a significant gain in computational efficiency. ${ }^{64-67}$ The cluster binding energies are calculated as

$$
\Delta E_{\text {binding }}=E_{\text {cluster }}-\sum_{i} E_{\text {monomer }, i}
$$

The final Gibbs free binding energy value is calculated as an average of the three functionals (M06-2X, PW91, and $\omega$ B97XD), which we will refer to as DLPNO//DFT. The structure for which the calculated DLPNO//DFT Gibbs free energy is the lowest is used for the analysis and further calculations (see Supporting Information). The cluster Gibbs free binding energies (eq 3) are calculated as the sum of the average DLPNO//DFT binding energy and the average DFT thermal contribution to the Gibbs free energy as

$$
\Delta G_{\text {binding }}=\Delta E_{\text {binding }}+\Delta G_{\text {Therm }}
$$

2.2. Kinetics and Cluster Population Dynamics. At given conditions, a cluster is considered to be stable against evaporation when its collision rate with vapor molecules (or clusters) is equal to or higher than its evaporation rate. ${ }^{68,69}$ According to the law of mass balance, the formation of cluster $(i+j)$ from clusters or molecules $i$ and $j$ as

$$
i+j \rightleftharpoons(i+j)
$$

has the equilibrium constant $K$

$$
K=\frac{C_{i+j}^{\mathrm{eq}}}{\left(C_{i}^{\mathrm{eq}}\right)\left(C_{j}^{\mathrm{eq}}\right)}=\frac{k_{\mathrm{B}} T}{p_{\text {ref }}} \exp \left(-\frac{\Delta G}{k_{\mathrm{B}} T}\right)
$$

where $C_{i}^{\mathrm{eq}}$ is the equilibrium concentration of species $i, k_{\mathrm{B}}$ is the Boltzmann constant, $T$ is the temperature, $\Delta G$ is the Gibbs free energy of reaction $\mathrm{R} 1$, and $p_{\text {ref }}$ is the reference pressure at which $\Delta G$ is calculated. At equilibrium and assuming detailed balance,

$$
\gamma_{(i+j) \rightarrow i, j} C_{i+j}^{\mathrm{eq}}=\beta_{i, j} C_{i}^{\mathrm{eq}} C_{j}^{\mathrm{eq}}
$$

where $\gamma_{(i+j) \rightarrow i, j}$ is the evaporation rate constant and $\beta_{i, j}$ is the collision rate constant. From eqs 4 and 5 , the evaporation rates of the clusters are obtained from the Gibbs free binding energies of the evaporating cluster and its products as

$$
\gamma_{(i+j) \rightarrow i, j}=\beta_{i, j} \frac{p_{\text {ref }}}{k_{\mathrm{B}} T} \exp \left(\frac{\Delta G_{i+j}-\Delta G_{i}-\Delta G_{j}}{k_{\mathrm{B}} T}\right)
$$

Note that the reference pressure $p_{\text {ref }}$ will cancel out when calculating the evaporation rate, and it does not need to correspond to the actual ambient pressure.

The collision coefficients are computed from kinetic gas theory ${ }^{70}$ as

$$
\beta_{i, j}=\left(\frac{3}{4 \pi}\right)^{1 / 6}\left[6 k_{\mathrm{B}} T\left(\frac{1}{m_{i}}+\frac{1}{m_{j}}\right)\right]^{1 / 2}\left(V_{i}^{1 / 3}+V_{j}^{1 / 3}\right)^{2}
$$

where $m_{i}$ and $V_{i}$ are the mass and volume of cluster $i$, respectively. The volumes are calculated using bulk liquid densities (1830 $\frac{\mathrm{kg}}{\mathrm{m}^{3}}$ for sulfuric acid and $1550 \frac{\mathrm{kg}}{\mathrm{m}^{3}}$ for guanidine) assuming spherical clusters and ideal mixing.

The time evolution and behavior of a population of clusters of different sizes and compositions are obtained by integrating the time derivatives of the cluster concentrations. These birthdeath equations include all possible processes where the clusters can be formed or destroyed. The cluster population dynamics have been simulated using the Atmospheric Cluster Dynamics Code (ACDC) ${ }^{42}$ which generates the birth-death equations for a given set of clusters and solves them explicitly by numerical integration using the ode $15 \mathrm{~s}$ solver of MATLAB. ${ }^{71}$ Here we examine steady-state situations, obtained by running the dynamic simulations until the cluster concentrations converge. The birth-death equation for each cluster is written as

$$
\begin{aligned}
\frac{\mathrm{d} C_{i}}{\mathrm{~d} t}= & \frac{1}{2} \sum_{j<i} \beta_{j,(i-j)} C_{j} C_{(i-j)}+\sum_{j} \gamma_{(i+j) \rightarrow i, j} C_{(i+j)} \\
& -\sum_{j} \beta_{i, j} C_{i} C_{j}-\frac{1}{2} \sum_{j<i} \gamma_{i \rightarrow j, i-j} C_{i}+S_{i}-L_{i} C_{i}
\end{aligned}
$$

where $C_{i}$ is the concentration of cluster $i, \beta_{i, j}$ is the collision rate coefficient between $i$ and $j, \gamma_{(i+j) \rightarrow i, j}$ is the evaporation rate coefficient of cluster $(i+j), S_{i}$ is an external source term, and $L_{i}$ is an external loss term corresponding to coagulation onto preexisting surfaces. The positive terms correspond to all collision and evaporation processes that create cluster $C_{i}$, and the negative terms correspond to all processes where the cluster is lost. In this work, the cluster-size-dependent loss rate coefficients $L_{i}$ are set to correspond to removal of clusters by collisions with larger background aerosol particles according to the power-law derived in ref 72 . The reference loss rate, corresponding to a sulfuric acid molecule, was set to $10^{-3} \mathrm{~s}^{-1}$, and the scavenging coefficient $m$ was set to -1.6.

2.3. ESI-APi-TOF Experiments. The laboratory experiments were carried out using a mass spectrometer. Clusters of sulfuric acid and guanidine were generated in the laboratory by electrospray ionization (ESI) using a $100 \mathrm{mM}$ sulfuric acid and $50 \mathrm{mM}$ guanidine solution in a water/methanol $1 / 1 \mathrm{v} / \mathrm{v}$. The solution was sprayed in negative mode; therefore only negatively charged clusters could be produced. The clusters were detected by APi-TOF (Tofwerk) mass spectrometer operating in negative mode. The negative mode is selected in order to be able to compare the results with field measurements, in which the negative mode is often used for detecting sulfuric acid and its clusters. The ratio of 2:1 of sulfuric acid and guanidine in the solution is used to optimize the experimental 
conditions and because atmospheric sulfuric acid concentration is expected to be higher than guanidine concentration. The data were analyzed using a Matlab based set of programs (tofTools) developed at the University of Helsinki. More details about the instrument can be found in ref 73 .

\section{RESULTS AND DISCUSSION}

3.1. Cluster Thermodynamics. The DLPNO-CCSD $(\mathrm{T})$ method was benchmarked against an explicitly correlated RICCSD(T)-F12 method, ${ }^{74}$ showing that DLPNO-CCSD(T)/ aug-cc-pVTZ yields results are in good agreement with the RI$\operatorname{CCSD}(\mathrm{T})-\mathrm{F} 12 / \mathrm{cc}-\mathrm{pVQZ}-\mathrm{F} 12$ level of theory (see Supporting Information).

Figure 2 presents the molecular structures for (HNC$\left.\left(\mathrm{NH}_{2}\right)_{2}\right)_{1-4}\left(\mathrm{H}_{2} \mathrm{SO}_{4}\right)_{1-4}$ clusters. For simplicity, we will refer to

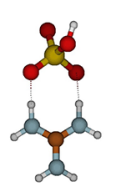

1G1A
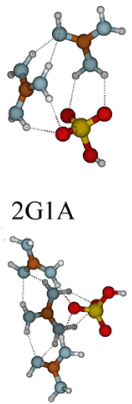

$3 \mathrm{G} 1 \mathrm{~A}$

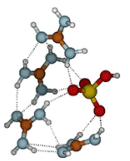

$4 \mathrm{G} 1 \mathrm{~A}$

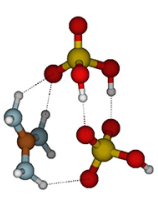

$1 \mathrm{G} 2 \mathrm{~A}$

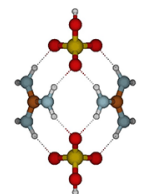

$2 \mathrm{G} 2 \mathrm{~A}$

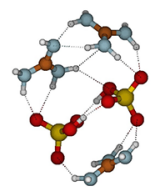

$3 \mathrm{G} 2 \mathrm{~A}$

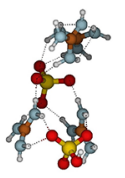

$4 \mathrm{G} 2 \mathrm{~A}$

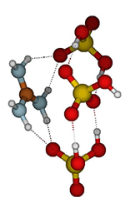

$1 \mathrm{G} 3 \mathrm{~A}$

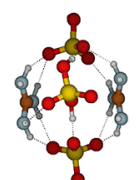

$2 \mathrm{G} 3 \mathrm{~A}$

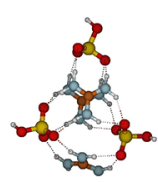

$3 \mathrm{G} 3 \mathrm{~A}$

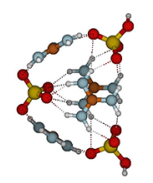

$4 \mathrm{G} 3 \mathrm{~A}$

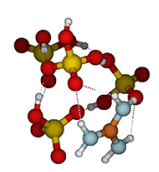

$1 \mathrm{G} 4 \mathrm{~A}$

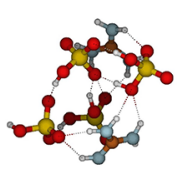

2G4A
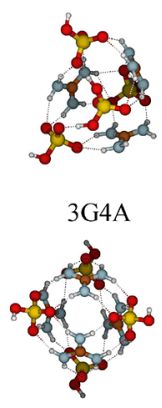

4G4A
Figure 2. Molecular structures of the studied two-component clusters. A refers to sulfuric acid and $G$ to guanidine. Color coding: blue is nitrogen, brown is carbon, red is oxygen, yellow is sulfur, and white is hydrogen. guanidine as $\mathrm{G}$ and to sulfuric acid as $\mathrm{A}$, and a cluster consisting of $n$ guanidine and $m$ acid molecules will be abbreviated as $n \mathrm{G} m \mathrm{~A}$.

Figure 3 shows the Gibbs free reaction energy diagram at $298.15 \mathrm{~K}$ and $1 \mathrm{~atm}$. Highly exergonic reaction steps are marked as green, and as can be seen, the guanidine-sulfuric acid clusters can form the 4G4A cluster with highly favorable monomer addition steps.

The Gibbs free energy of formation of the 1G1A cluster is $-20.2 \mathrm{kcal} / \mathrm{mol}$ at $298.15 \mathrm{~K}$ and $1 \mathrm{~atm}$. The very high stability of $1 \mathrm{G} 1 \mathrm{~A}$ can be explained by the proton transfer from sulfuric acid to guanidine and two strong intermolecular interactions between bisulfate and guanidinium. The guanidinium ion is planar, symmetric, and Y-aromatic, and it is able to form nearly linear hydrogen-bonds with bisulfate with $\mathrm{N}-\mathrm{H}-\mathrm{O}$ angles of $174-177^{\circ}$. Adding a second sulfuric acid molecule to the $1 \mathrm{G} 1 \mathrm{~A}$ cluster is exergonic by $-17.7 \mathrm{kcal} / \mathrm{mol}$, and the number of intermolecular bonds increases from two to five. The additions of a third and fourth sulfuric acid molecule increase the number of intermolecular interactions to 8 and 13, respectively. The Gibbs free energies of the third and fourth additions are -12.8 and $-7.6 \mathrm{kcal} / \mathrm{mol}$, respectively.

The addition of guanidine to the cluster with one guanidine and two to four sulfuric acid molecules is highly exergonic with Gibbs free reaction energies more negative than $-30 \mathrm{kcal} / \mathrm{mol}$. The addition of a second guanidine to the $1 \mathrm{G} 1 \mathrm{~A}$ cluster increases the number of intermolecular interactions to six; however, the interactions are relatively weak, and thus the reaction free energy is only $-8.0 \mathrm{kcal} / \mathrm{mol}$. The third and fourth guanidine additions only increase the number of weak intermolecular interactions, and the reaction free energies are -9.8 and $-7.4 \mathrm{kcal} / \mathrm{mol}$, respectively. This indicates that once the $1 \mathrm{G} 1 \mathrm{~A}$ cluster has been formed, the next favorable step is the formation of the 1G2A cluster, followed by the formation of the $2 \mathrm{G} 2 \mathrm{~A}$ cluster. Alternatively, the $2 \mathrm{G} 2 \mathrm{~A}$ cluster can be formed via collision of two 1G1A heterodimer, for which the Gibbs free reaction energy is $-47.8 \mathrm{kcal} / \mathrm{mol}$. The $2 \mathrm{G} 2 \mathrm{~A}$ cluster has symmetrical molecular structure $\left(C_{2 v}\right.$ point group $)$ and eight strong intermolecular bonds, which explains its very low Gibbs free binding energy value $-68.0 \mathrm{kcal} / \mathrm{mol}$.

The additions of a third and fourth sulfuric acid molecule to the $2 \mathrm{G} 2 \mathrm{~A}$ cluster are exergonic by -14.1 and $-10.0 \mathrm{kcal} / \mathrm{mol}$, respectively. Adding the third and fourth guanidine molecules to the 2G2A cluster is only slightly exergonic with reaction free energies of -5.3 and $-9.8 \mathrm{kcal} / \mathrm{mol}$, respectively. The

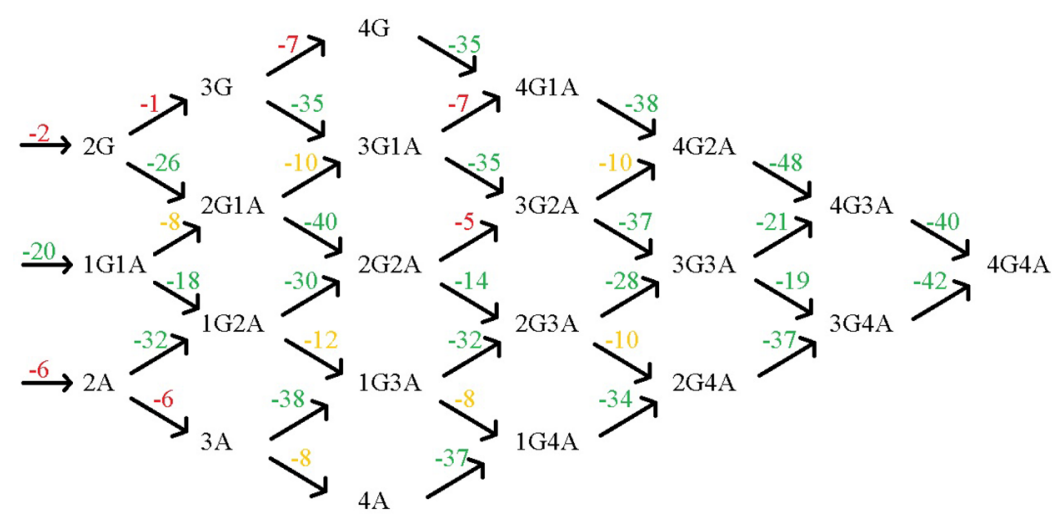

Figure 3. Reaction free energy ( $\mathrm{kcal} / \mathrm{mol}$ ) diagram for guanidine-sulfuric acid clusters at $298.15 \mathrm{~K}$ and 1 atm. A refers to sulfuric acid and $\mathrm{G}$ to guanidine. Color coding: green is $<-13$, yellow is from -13 to -8 , and red is $>-8 \mathrm{kcal} / \mathrm{mol}$. 
intermolecular bonds in the 2G3A molecular structure are stronger than in the $3 \mathrm{G} 2 \mathrm{~A}$ structure, which leads to the higher thermodynamic stability of $2 \mathrm{G} 3 \mathrm{~A}$ cluster over $3 \mathrm{G} 2 \mathrm{~A}$. The same pattern has been seen for monoamines and ammonia. ${ }^{75}$

The stability of the $3 \mathrm{G} 3 \mathrm{~A}$ cluster is very high, with a Gibbs free binding energy of $-110.0 \mathrm{kcal} / \mathrm{mol}$. All sulfuric acid molecules donate one proton to the guanidine molecules, and every bisulfate ion is interacting with two or three guanidinium ions, and every guanidinium binds with two or three bisulfates. The addition of a fourth sulfuric acid or guanidine molecule is highly exergonic, with reaction free energies of -18.7 and $-21.2 \mathrm{kcal} / \mathrm{mol}$, respectively. The formation of the extraordinarily stable 4G4A cluster by monomer additions is thermodynamically very favorable.

The Gibbs free binding energy of 4G4A is as low as -170.9 $\mathrm{kcal} / \mathrm{mol}$, which can be explained by the mesh-like molecular structure. In the $4 \mathrm{G} 4 \mathrm{~A}$ cluster structure, four proton transfer reactions occur; i.e., each of the sulfuric acid molecules donates one proton to a guanidine. Every bisulfate ion is interacting with three guanidinium ions and vice versa, while the hydroxyl group in bisulfate structure remains vacant. The spherical structure, where the free hydroxyl groups of the bisulfates are on the outer side, indicates that the cluster is able to interact with other molecules, e.g., by uptaking some oxidized organic compounds. The high symmetry and stability of the $n \mathrm{G} n \mathrm{~A}$ diagonal clusters suggest that larger clusters with equal number of acid and base molecules might also be very stable.

3.2. Molecular-Level Cluster Formation and Evaporation. 3.2.1. Vapor Concentration-Dependent Gibbs Free Energy Surface. Gibbs free formation energies yield insight into the relative cluster stabilities, but to get information about growth pathways or relative abundances, kinetic effects must be taken into account. The Gibbs free binding energies $\Delta G_{\text {binding }}$ calculated at the reference pressure $p_{\text {ref }}$ do not include the effect of the vapor-phase concentrations of the clustering species. From the law of mass action the actual vapor concentration-dependent Gibbs free energies of the clusters at given vapor concentrations $C_{i}$ can be obtained as

$$
\Delta G_{\text {actual }}\left(C_{1}, C_{2}, \ldots, C_{n}\right)=\Delta G_{\text {binding }}-k_{\mathrm{B}} T \sum_{i=1}^{n} N_{i} \ln \left(\frac{C_{i}}{C_{\text {ref }}}\right)
$$

where the summation goes over all compounds $i$ in the cluster, and $C_{\text {ref }}=p_{\text {ref }} /\left(k_{\mathrm{B}} T\right)$. To examine the clustering thermodynamics at atmospheric conditions, we calculated the actual free energies at concentrations of [sulfuric acid] $=10^{6} \mathrm{~cm}^{-3}$ and [guanidine] $=1 \operatorname{ppt}_{V}\left(\sim 10^{7}\right.$ molecules $\left.\mathrm{cm}^{-3}\right)$ as shown in Figure 4.

A key question concerning cluster growth is the existence of free energy barriers, i.e., critical cluster sizes, which have equal probabilities to grow and to decay. Figure 4 shows that at the studied conditions, there are no thermodynamic barriers along the main growth pathways (see Figure 6) in the guanidinesulfuric acid system. Therefore, this new-particle formation mechanism is not nucleation but kinetically limited cluster growth in which each growth step is thermodynamically favorable.

Due to the fact that the atmospheric concentration of guanidine is not well-known and might be orders of magnitude lower than the used estimate, we calculated the actual Gibbs free energy surfaces also at guanidine concentrations as low as $10^{-3} \operatorname{ppt}_{V}\left(\sim 10^{4} \mathrm{~cm}^{-3}\right)$ and $10^{-6} \operatorname{ppt}_{V}\left(\sim 10 \mathrm{~cm}^{-3}\right)$ while

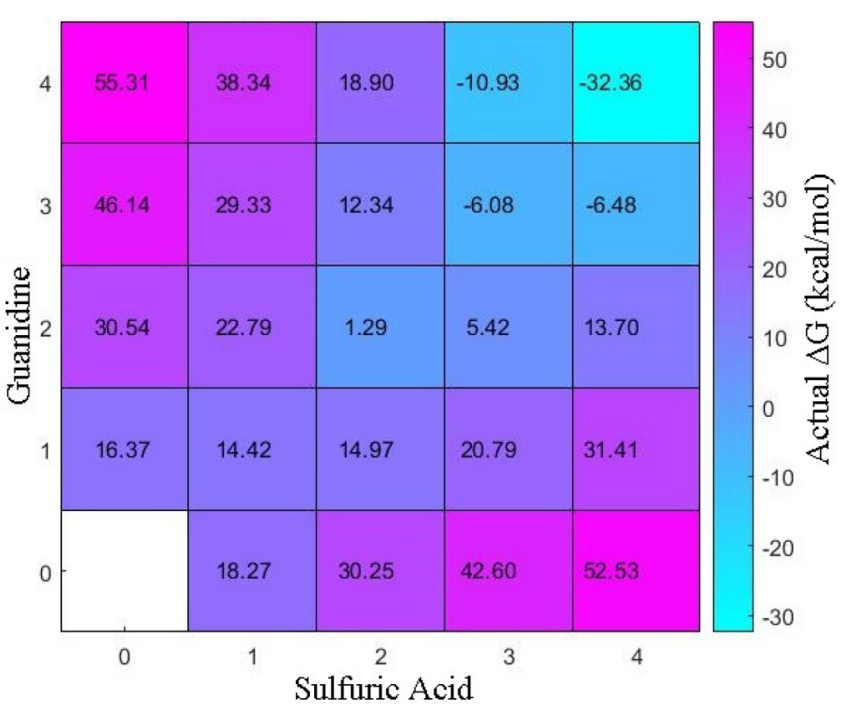

Figure 4. Actual Gibbs free energies for guanidine-sulfuric acid clusters at $298.15 \mathrm{~K},[\mathrm{~A}]=10^{6} \mathrm{~cm}^{-3}$, and $[\mathrm{G}]=1 \operatorname{ppt}_{V}\left(\sim 10^{7} \mathrm{~cm}^{-3}\right)$. The $x$ - and $y$-axes give the numbers of sulfuric acid and guanidine molecules in the cluster, respectively.

keeping the sulfuric acid concentration at $10^{6} \mathrm{~cm}^{-3}$ (see Supporting Information). Results show that even at the concentration of only 10 guanidine molecules per cubic centimeter, the are no major barriers in the growth of the guanidine-sulfuric acid clusters. Thus, even if the atmospheric abundance of guanidine is very low, guanidine is still likely to be able to participate in the initial steps of new-particle formation, under the premise that it collides with a sulfuric acid molecule.

3.2.2. Evaporation Rates. Figure 5 presents the overall evaporation rates $\sum \gamma$ for the guanidine-sulfuric acid clusters at

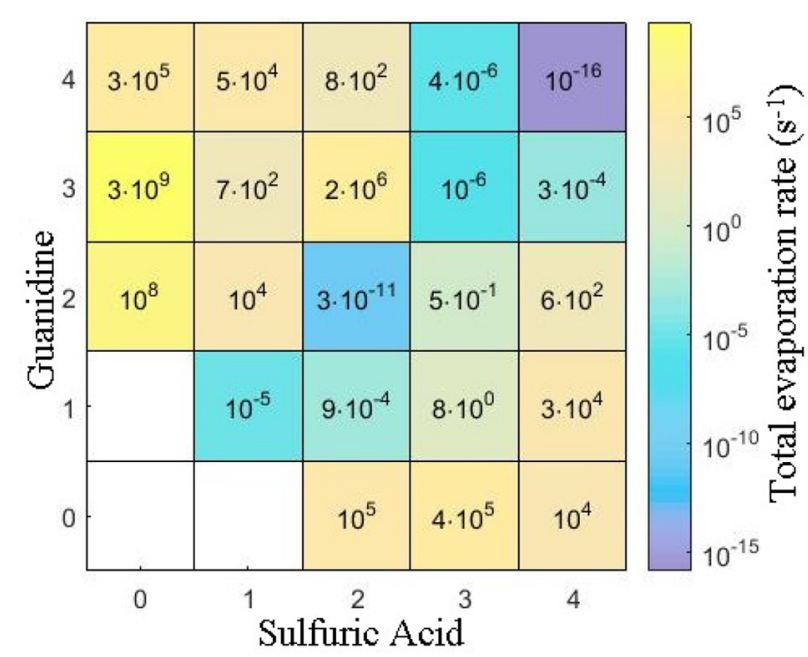

Figure 5. Overall evaporation rates $\left(\sum \gamma\left(\mathrm{s}^{-1}\right)\right)$ for guanidine-sulfuric acid clusters at $298.15 \mathrm{~K}$.

298.15 K, calculated for each cluster as the sum of all evaporation rates (eq 6) of all possible evaporation pathways of the cluster. All $\sum \gamma$ are found to be low when the number of acid molecules in the cluster is equal to the number of base molecules $(n \mathrm{G} n \mathrm{~A})$ or when there is one acid molecule more compared to the number of base molecules $(n \mathrm{G}(n+1) \mathrm{A})$.

At vapor concentrations $C_{i}$ of, for instance, $10^{5}-10^{8} \mathrm{~cm}^{-3}$, the molecular collision frequencies $\beta_{i, \text { cluster }} \times C_{i}$ are of the order 
$\sim 10^{-4}-10^{-1} \mathrm{~s}^{-1}$. The evaporation rates for $n \mathrm{G} n \mathrm{~A}$ diagonal clusters are in the range of $10^{-16}-10^{-5} \mathrm{~s}^{-1}$, indicating that collisions are likely to occur more often than evaporation events, and the cluster growth is collision-driven. The ratios for sulfuric acid and guanidine monomer collision frequencies versus evaporation event frequencies are presented in Supporting Information. Results suggest that even at low concentrations, strongly basic compounds such as guanidine might be a key species in the first steps of new-particle formation, as the clusters are not prone to re-evaporation.

It should be mentioned that some studies have reported very stable clusters and barrierless clustering also for other atmospheric systems, such as dimethylamine and sulfuric acid. ${ }^{18,75,76}$ In those studies the RI-CC2/aug-cc-pV(T+d)Z// B3LYP/CBSB7 level of theory (referred as B3RICC2) ${ }^{77}$ has been applied to calculate the thermodynamic data. Now several problems related to the B3RICC2 approach should be brought up (for detailed discussion, see ref 78). The B3LYP functional without dispersion corrections is not recommended for noncovalently bound systems where dispersion interactions have a significant role. $^{79}$ The CBSB7 basis set (which corresponds to 6-311G $(2 \mathrm{~d}, \mathrm{~d}, \mathrm{p})$ ) does not contain any diffuse functions and thus is not suitable for systems containing ion pairs. ${ }^{57,80}$ The main problem is, however, the usage of RI-CC2 method to calculate single point energies. The CC2 method is developed for excited states and accordingly overestimates the correlation effect of ground states. ${ }^{81,82}$ This means that binding energies are way too negative, even more than when using MP2. ${ }^{83-85}$ The CC2 method should not be applied to calculate binding energies of ground state systems, ${ }^{86}$ as the errors are up to tens of $\mathrm{kcal} / \mathrm{mol}$ (for acid-base clusters up to 10 molecules). ${ }^{65}$ When thermodynamic data obtained by B3RICC2 are used to calculate cluster evaporation rates (an exponential dependence on the stepwise Gibbs free energies), the results can be significantly too low, possibly leading to the conclusion of barrierless cluster formation.

3.2.3. Main Cluster Growth Pathways. To understand the molecular-level clustering mechanisms, the main step-by-step cluster formation pathways were solved by performing ACDC simulations and tracking the growth routes from the simulation data. ${ }^{18}$ Figure 6 presents the main growth pathways at 298.15 $\mathrm{K},[\mathrm{A}]=10^{6} \mathrm{~cm}^{-3}$, and $[\mathrm{G}]=1 \operatorname{ppt}_{V}\left(\sim 10^{7} \mathrm{~cm}^{-3}\right)$. Cluster

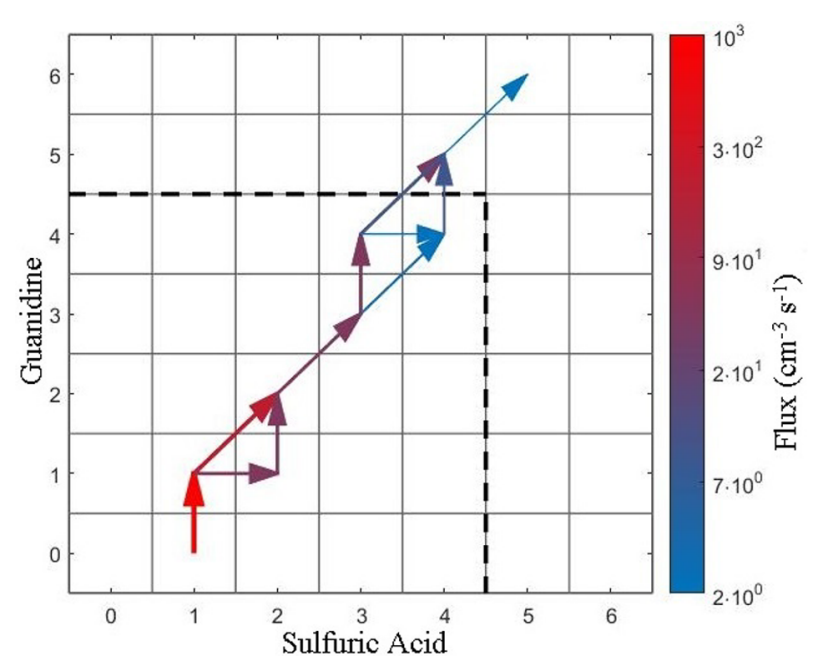

Figure 6. Main cluster growth pathway for guanidine-sulfuric acid clusters at $298.15 \mathrm{~K},[\mathrm{~A}]=10^{6} \mathrm{~cm}^{-3}$, and $[\mathrm{G}]=1 \operatorname{ppt}_{V}\left(\sim 10^{7} \mathrm{~cm}^{-3}\right)$. growth is most likely to occur along the diagonal, which is consistent with high thermodynamic stability of $n \mathrm{G} n \mathrm{~A}$ clusters.

When the 1G1A cluster has formed, the majority of these clusters grow by the addition of a second 1G1A cluster. The $2 \mathrm{G} 2 \mathrm{~A}$ cluster collides again with $1 \mathrm{G} 1 \mathrm{~A}$ and forms the $3 \mathrm{G} 3 \mathrm{~A}$ complex. The main growth step of $3 \mathrm{G} 3 \mathrm{~A}$ is the addition of a guanidine monomer, followed by growth out of the simulation system through the addition of $1 \mathrm{G} 1 \mathrm{~A}$ to the 4G3A cluster. Growth pathways at lower guanidine concentrations are presented in Supporting Information.

Elm et al. recently reported efficient cluster formation between diamines and sulfuric acid. ${ }^{24}$ Compared to the growth pathway of putresine-sulfuric acid clusters which occurs in the acid/base ratio of $2: 1$, the cluster growth of guanidine with sulfuric acid is more similar to that of monoamines such as dimethylamine, i.e., occurring in the acid/base ratio of $1: 1 .^{75}$

3.2.4. Laboratory Experiments. In order to experimentally verify the main conclusions and to investigate in more detail the stability and the relative abundance of guanidine-sulfuric acid clusters, we carried out experiments in the laboratory using ESIAPi-TOF mass spectrometry. Negatively charged clusters were produced by ESI and detected using an APi-TOF mass spectrometer operating in negative mode. Therefore, clusters containing only guanidine were not detectable due to the strong basicity of the compound, which makes them very unlikely to be deprotonated in our conditions. In all the other clusters one sulfuric acid molecule will be deprotonated and form bisulfate (referred to as B). In our experimental conditions, we were only able to detect clusters containing at least one sulfuric acid more than guanidine. Indeed, also in previous studies in negative mode, clusters with the same number of base and acid molecules were observed only for large clusters (e.g., 10 acid and 10 base molecules), and clusters containing more base than acid molecules were not observed at all. ${ }^{87}$ This phenomenon is probably due to the lower stability of these negatively charged clusters. ${ }^{88}$ We detected homomolecular sulfuric acid clusters, as well as heteromolecular clusters with formula $n \mathrm{G} 1 \mathrm{~A} 1 \mathrm{~B}, n \mathrm{G} 2 \mathrm{~A} 1 \mathrm{~B}$, and $n \mathrm{G} 3 \mathrm{~A} 1 \mathrm{~B}$ with $1 \leq n \leq 3$ (see Figure 7). Larger clusters containing more than four sulfuric acid molecules were also observed, with the largest detected cluster being 5G5A1B.

Interestingly, for clusters with more than five acid molecules we observed the formation of tricomponent clusters where ammonia (present as gas-phase impurity) was bound to guanidine-sulfuric acid clusters. We identified 4G1N5A1B and 5G1N6A1B clusters, where ammonia is referred as N (see Supporting Information). The formation of large tricomponent clusters containing ammonia has also been observed in previous studies for dimethylamine-sulfuric acid clusters. ${ }^{87}$ This actually supports the hypothesis that strong bases are important in the initial steps and less basic compounds can contribute to the cluster growth at later stages, when the clusters are sufficiently large.

Our theoretical results indicated that the most stable electrically neutral clusters are those with the composition $n \mathrm{G} n \mathrm{~A}$. Although these clusters were not detected in our conditions, all other clusters that we expected to be more stable in negative mode (where the number of bases is smaller than that of acids) were observed in the mass spectrum. Note that we were able also to detect small clusters containing guanidine (1G1A1B). Usually small clusters containig sulfuric acid and bases are not detectable in negative mode. For example, the smallest ammonia-sulfuric acid cluster detectable by an APi- 


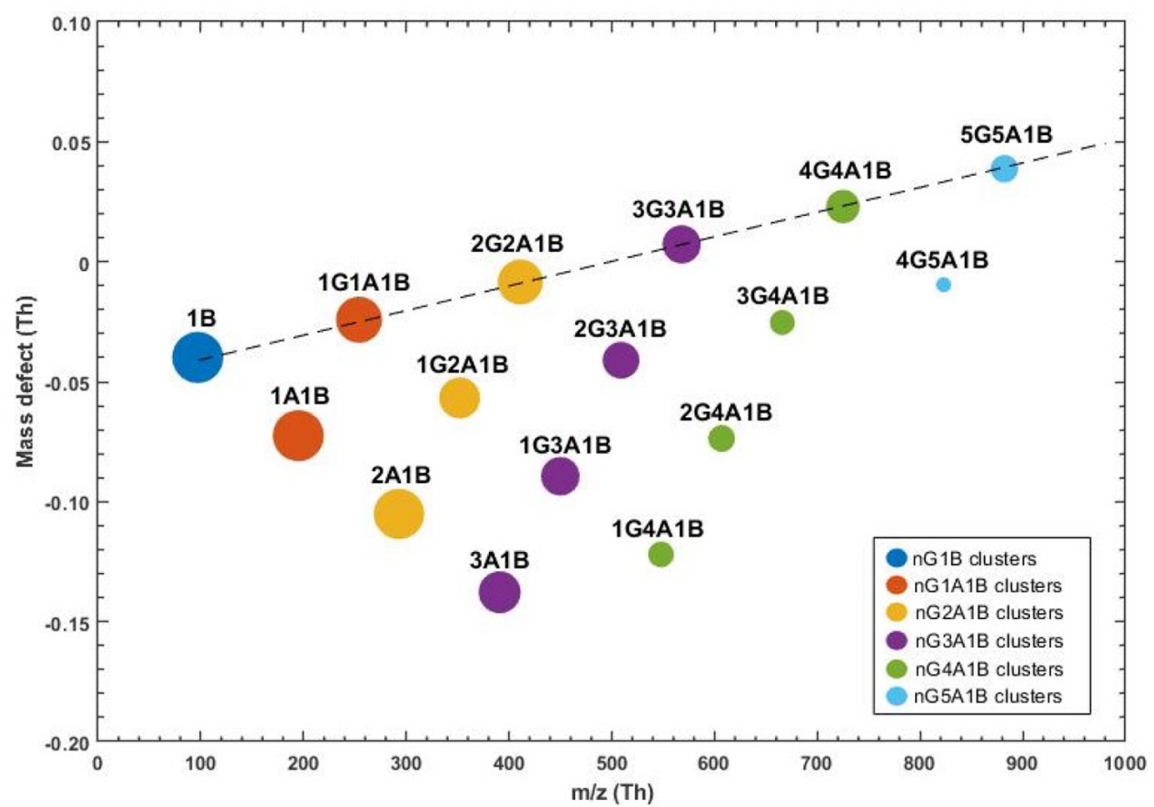

Figure 7. Mass defect plot of the negative clusters produced by ESI. The size of the symbols is proportional to the logarithm of the count rate. The dashed line highlights the clusters with formula $n \mathrm{G} n \mathrm{~A} 1 \mathrm{~B}(0 \leq n \leq 5)$.

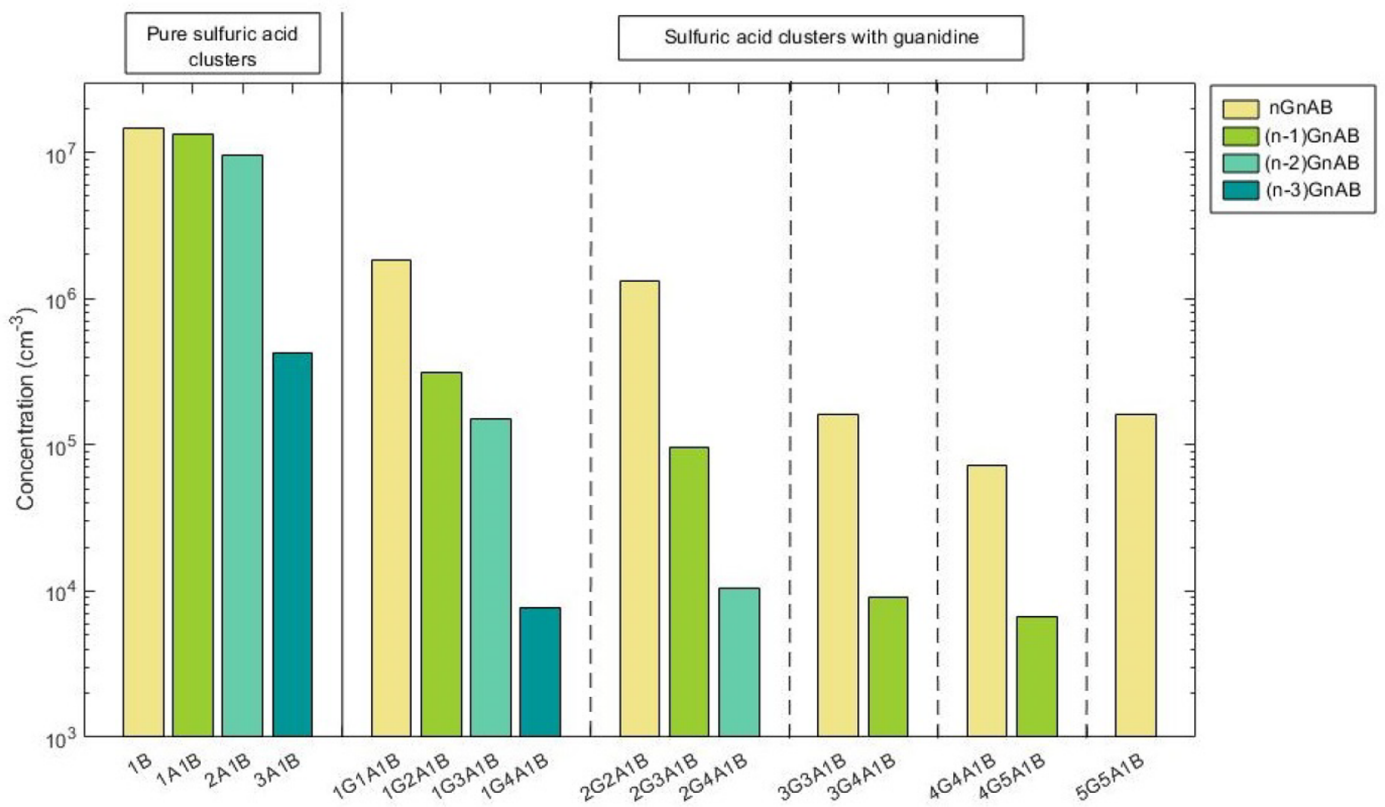

Figure 8. Measured distribution of negatively charged guanidine-sulfuric acid clusters.

TOF is that containing one ammonia, three sulfuric acids, and one bisulfate, while for amines and diamines the smallest clusters observed have been composed of one amine/diamine, two sulfuric acids, and one bisulfate. ${ }^{24,87}$ The observation of small clusters such as 1 G1A1B by the APi-TOF in negative mode is probably due to the higher stability of guanidinesulfuric acid clusters compared to other sulfuric acid-base clusters.

The measured cluster distribution (see Figure 8) shows that homomolecular sulfuric acid clusters are the most abundant ones. This could be a consequence of the experimental conditions: the solution used to generate clusters contained sulfuric acid and guanidine in a molar ratio of 2:1. Moreover, some of the pure sulfuric acid clusters are particularly stable when negatively charged; for example, the evaporation rate of $1 \mathrm{~A} 1 \mathrm{~B}$ is several orders of magnitude lower than the corresponding neutral cluster $(2 \mathrm{~A}) .^{66,88}$ However, $n \mathrm{G} n \mathrm{~A} 1 \mathrm{~B}$ clusters have a relatively high concentration, whereas the clusters with lower base-acid ratio are less abundant. These results are in agreement with the calculated Gibbs free binding energies for the neutral clusters, for which we showed that the diagonal $(n \mathrm{G} n \mathrm{~A})$ and near to the diagonal $((n \pm 1) \mathrm{G} n \mathrm{~A})$ are the most stable compositions. In general, the measurements further confirm the ability of guanidine to act as a highly efficient stabilizer of sulfuric acid clusters.

3.3. ACDC Simulations and Comparison with Dimethylamine Clusters. To connect the results on the cluster stabilities to atmospheric observations and predictions, the 

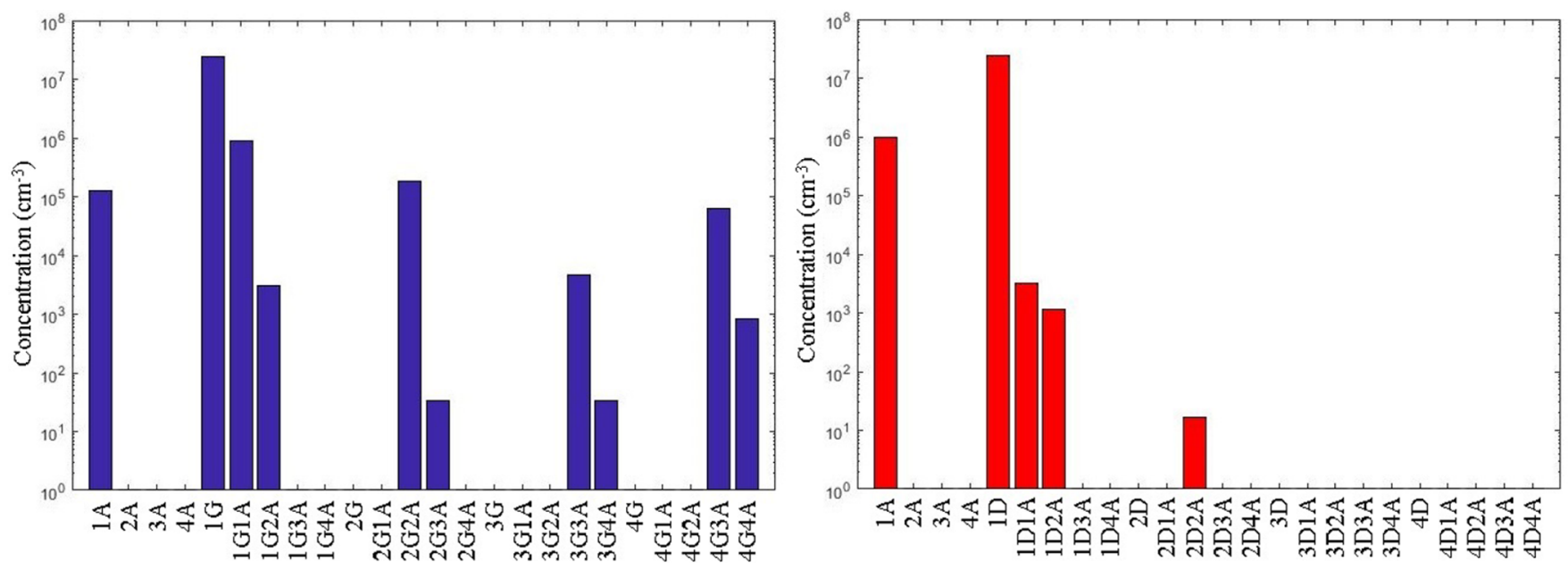

Figure 9. Steady-state distribution of guanidine-sulfuric acid (left) and dimethylamine-sulfuric acid (right) clusters at $298.15 \mathrm{~K}, \sum[1 \mathrm{~A} n \mathrm{Base}]=10^{6}$ $\mathrm{cm}^{-3}$, and $[$ Base $]=1 \operatorname{ppt}_{V}\left(\sim 10^{7} \mathrm{~cm}^{-3}\right)$. Note the logarithmic scale of the steady state concentrations.

ACDC simulations of cluster population dynamics were performed at atmospherically relevant conditions. For a reference, we simulated also clusters consisting of sulfuric acid and dimethylamine. Thermodynamic data for the dimethylamine clusters are from ref 89 , where the used computational level is $\mathrm{DLPNO}-\mathrm{CCSD}(\mathrm{T}) /$ aug-cc-pVTZ// $\omega \mathrm{B} 97 \mathrm{X}-\mathrm{D} / 6-31++\mathrm{G}^{* *}$, and thus, the same level of theory is also used for guanidine clusters in this section. Gibbs free binding energies are calculated using rigid rotor-harmonic oscillator approximation at $298.15 \mathrm{~K}$, and they are presented in Supporting Information for all clusters. Dimethylamine will be simply referred to as $\mathrm{D}$.

In these simulations, the concentrations of sulfuric acid and guanidine or dimethylamine were once again set to fixed values; however, to compare the results to atmospheric measurements, the concentration of sulfuric acid was defined as the total concentration of all clusters containing one sulfuric acid molecule and any number of base molecules. This is because chemical ionization mass spectrometers that are used to measure ambient sulfuric acid vapor concentration are likely to detect also clustered acid molecules.

3.3.1. Steady-State Cluster Distribution. Figure 9 shows the steady-state guanidine-sulfuric acid cluster distribution at $298.15 \mathrm{~K}$, when the measurable sulfuric acid concentration is set to $10^{6}$ molecules $\mathrm{cm}^{-3}$ (i.e., the sum of $1 \mathrm{~A}, 1 \mathrm{G} 1 \mathrm{~A}, 2 \mathrm{G} 1 \mathrm{~A}$, $3 \mathrm{G} 1 \mathrm{~A}$, and $4 \mathrm{G} 1 \mathrm{~A}$ concentrations $\sum[n \mathrm{G} 1 \mathrm{~A}]$ is $10^{6}$ molecules $\left.\mathrm{cm}^{-3}\right)$. The concentration of guanidine is set to $1 \mathrm{ppt}_{V}\left(\sim 10^{7}\right.$ $\left.\mathrm{cm}^{-3}\right)$. Steady-state dimethylamine-sulfuric acid cluster distribution is also calculated at same conditions and settings (see Figure 9).

The concentrations of the diagonal $n \mathrm{G} n \mathrm{~A}$ clusters (1G1A, $2 \mathrm{G} 2 \mathrm{~A}, 3 \mathrm{G} 3 \mathrm{~A}$, and $4 \mathrm{G} 4 \mathrm{~A}$ ) are high, varying from $10^{3}$ to $10^{6}$ $\mathrm{cm}^{-3}$. Also the $n \mathrm{G}(n+1) \mathrm{A}$ clusters have relatively high concentrations. In addition, the 4G3A cluster has a concentration of almost $10^{5} \mathrm{~cm}^{-3}$, which is consistent with its low evaporation rate $\left(4 \times 10^{-6} \mathrm{~s}^{-1}\right)$. In the case of dimethylamine, only $1 \mathrm{D} 1 \mathrm{~A}$ and $1 \mathrm{D} 2 \mathrm{~A}$ clusters exhibit concentrations that are even slightly higher than $10^{3} \mathrm{~cm}^{-3}$. The basicity of the base significantly influences the formation and stability of the heterodimer (1G1A or 1D1A). Due to the fact that the concentration of the heterodimer strongly affects the formation of larger clusters, the main limitation of forming larger dimethylamine clusters is the low concentration of $1 \mathrm{D} 1 \mathrm{~A}$ $\left(3 \times 10^{3} \mathrm{~cm}^{-3}\right)$. The weak formation of the $1 \mathrm{D} 1 \mathrm{~A}$ cluster is also confirmed by ESI-APi-TOF measurements in ref 87 .

Under the studied conditions, the formation of the smallest dimethylamine-sulfuric acid clusters $(n \mathrm{D} n \mathrm{~A}$, for $n$ up to 2$)$ is a stochastic process, which involves sequential formation and decomposition of clusters. In contrast for guanidine-sulfuric acid clusters this process is barrierless, and the particle formation is collision-driven. For dimethylamine-sulfuric acid clusters to reach the same heterodimer concentration as in the case of guanidine-sulfuric acid clusters, $2200 \mathrm{ppt}_{V}\left(\sim 10^{10}\right.$ $\mathrm{cm}^{-3}$ ) of dimethylamine is required when other conditions remain the same (see Supporting Information).

3.3.2. Total Concentration of Clusters Containing Two Sulfuric Acid Molecules. As the formation of sulfuric acid "dimers" is an important initial step in sulfuric-acid-driven particle formation, we have studied the enhancing effect of guanidine also through the dimer concentration. Here the "dimer" concentration is defined as the sum of the concentrations of all clusters containing two sulfuric acid molecules and any number of base molecules. This quantity can be directly measured and has been used to characterize cluster formation in experimental studies both in laboratory ${ }^{20,90}$ and in field. ${ }^{91}$ Figure 10 shows the modeled steady-state dimer concentration $\left(\sum[n \mathrm{Base} 2 \mathrm{~A}]\right)$ as a function of measurable monomer concentration $\left(\sum[n\right.$ Base $\left.1 \mathrm{~A}]\right)$ at five different base mixing ratios.

In the case of guanidine, at $10^{6} \mathrm{~cm}^{-3}<\sum[n \mathrm{G} 1 \mathrm{~A}]<10^{7}$ $\mathrm{cm}^{-3}$, the dimer concentration increases 2 orders of magnitude with the 10 -fold increase in $\sum[n \mathrm{G} 1 \mathrm{~A}]$, but the increase begins to level off at $\sum[n \mathrm{G} 1 \mathrm{~A}]>10^{7} \mathrm{~cm}^{-3}$. By contrast in the case of dimethylamine, the dimer concentration increases always 2 orders of magnitude with a 10 -fold increase in $\sum[n \mathrm{D} 1 \mathrm{~A}]$ (except at $[\mathrm{D}]=10 \mathrm{ppt}_{V}\left(\sim 10^{8} \mathrm{~cm}^{-3}\right)$ ). This reflects the fact that the guanidine-sulfuric acid mixture reaches the kinetic limit of dimer formation at lower sulfuric acid concentration than the dimethylamine-sulfuric acid mixture. The guanidine system also reaches saturation with respect to the base concentration at $1 \mathrm{ppt}_{V}$ of guanidine $\left(\sim 10^{7} \mathrm{~cm}^{-3}\right)$, whereas for the dimethylamine system at the studied vapor concentrations, every 10-fold increase in the base concentration causes a 10 -fold increase in the dimer concentration. These results clearly show how strongly the basicity of the base affects its ability to cluster with sulfuric acid: The nonlinear trends in 


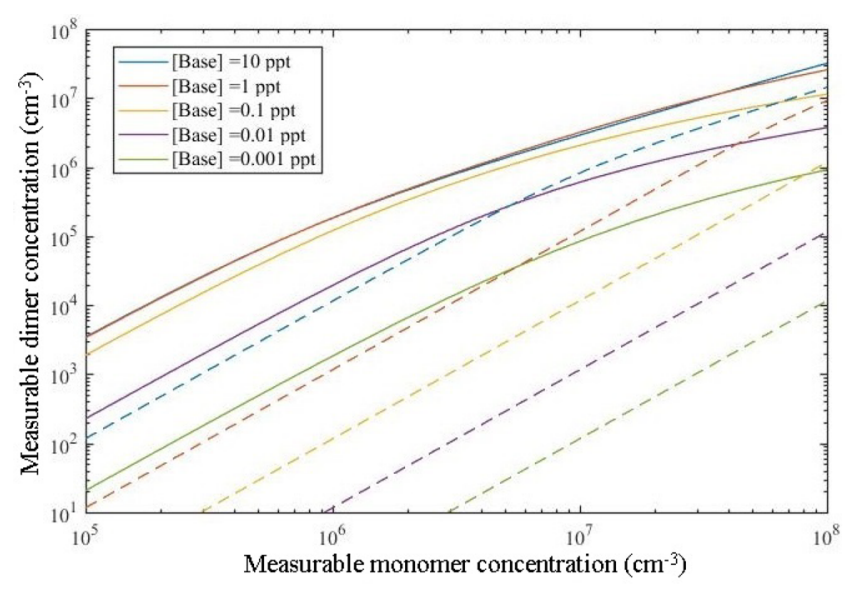

Figure 10. Steady-state concentrations of guanidine-sulfuric acid $\sum[n \mathrm{G} 2 \mathrm{~A}]$ (solid lines) and dimethylamine-sulfuric acid $\sum[n \mathrm{D} 2 \mathrm{~A}]$ (dashed lines) clusters containing two acids at $298.15 \mathrm{~K}$.

$\sum[n$ Base2A $]$ demonstrate that cluster stability is the key factor determining the dimer abundance for different chemical systems.

The modeled $\sum[n$ Base $2 \mathrm{~A}]$ are generally of the same order as field measurements reported for a rural site $\left(\sim 10^{3}-10^{5} \mathrm{~cm}^{-3}\right.$ at $\sum[n$ Base $\left.1 \mathrm{~A}] \approx 10^{6}-10^{7} \mathrm{~cm}^{-3}\right) .{ }^{91}$ While the stabilizing compounds for the field observations are not known, it is interesting to note that already $0.1 \mathrm{ppt}_{V}$ of guanidine $\left(\sim 10^{6}\right.$ $\mathrm{cm}^{-3}$ ) is able to increase cluster concentrations approximately an order of magnitude beyond the measured levels. This means that if present, strong bases such as guanidine may dominate the very initial steps of particle formation especially in unpolluted environments.

3.3.3. New-Particle Formation Rates. Steady-state particle formation rates, defined as the flux of stable clusters growing out from the simulated cluster size range, were obtained from the ACDC simulations. Figure 11 shows the new-particle formation (NPF) rates for guanidine-sulfuric acid and dimethylamine-sulfuric acid clusters at measurable sulfuric acid concentration in the range of $\sum[n$ Base $1 \mathrm{~A}]=10^{5}-10^{8}$ $\mathrm{cm}^{-3}$ and at five different base mixing ratios at $298.15 \mathrm{~K}$.

The general trends of the NPF rates are similar to those of the dimer concentrations: the guanidine-sulfuric acid particle

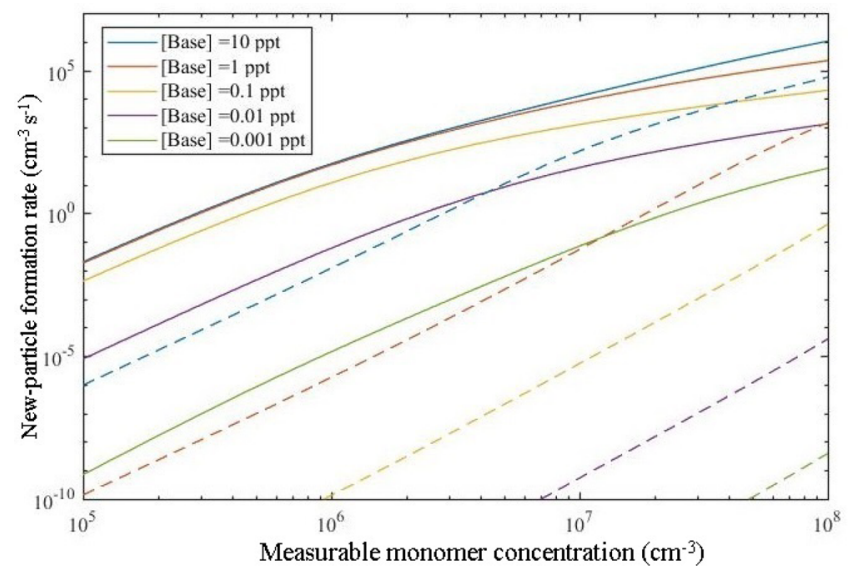

Figure 11. Steady-state particle formation rates for guanidine-sulfuric acid (solid lines) and dimethylamine-sulfuric acid (dashed lines) clusters at $298.15 \mathrm{~K}$. formation rate reaches saturation with respect to guanidine at a guanidine mixing ratio of $1 \mathrm{ppt}_{V}\left(\sim 10^{7} \mathrm{~cm}^{-3}\right)$, meaning that a further increase in the guanidine concentration does not significantly affect the NPF rate. By contrast, increasing the mixing ratio of dimethylamine by a factor of 10 increases the NPF rate by 4 orders of magnitude at the studied conditions. In general, at these conditions guanidine enhances NPF rates more than 8 orders of magnitude compared to dimethylamine.

The modeled NPF rates are in line with experimentally deduced values from atmospheric particle measurements: For instance, at sulfuric acid concentration of $\sum[n$ Base $1 \mathrm{~A}]=10^{5}$ $\mathrm{cm}^{-3}$ and $[\mathrm{G}]=1 \operatorname{ppt}_{V}\left(\sim 10^{7} \mathrm{~cm}^{-3}\right)$ the NPF rate is 0.02 particles $\mathrm{cm}^{-3} \mathrm{~s}^{-1}$, while values in the range of $0.001-1$ particles $\mathrm{cm}^{-3} \mathrm{~s}^{-1}$ have been reported for field observations. ${ }^{24}$ At $\sum[n$ Base1A $]=10^{6}-10^{7} \mathrm{~cm}^{-3}, 1 \mathrm{ppt}_{V}$ of guanidine $\left(\sim 10^{7}\right.$ $\mathrm{cm}^{-3}$ ) produces NPF rates of the order of $\sim 10-10000$ particles $\mathrm{cm}^{-3} \mathrm{~s}^{-1}$ which is close to or beyond the highest reported atmospheric NPF rates at same conditions. Therefore, at higher sulfuric acid concentrations, ppt $_{V}$ levels of dimethylamine or subppt ${ }_{V}$ levels of guanidine agree best with experiments. However, it must be noted that the experimental NPF rates cover a wide range of environmental conditions and involve contributions from various participating species. It is very likely that a large variety of different chemical compounds is needed to explain observed NPF events in the atmosphere. In addition, many observations are for larger $(\sim 3 \mathrm{~nm})$ particles, and due to scavenging losses, the rates can be expected to be lower than those determined for small clusters.

Hydration is neglected in this study. However, recent studies have shown that the effect of hydration depends strongly on the basicity of the base such that relatively strong bases (e.g., dimethylamine) are almost unaffected by hydration. ${ }^{75,92}$ We can thus assume that hydration of guanidine-sulfuric acid clusters does not have a significant effect on, for example, the NPF rates. It has also been shown that NPF rates of strong bases and sulfuric acid are only weakly temperature-dependent, ${ }^{75}$ and thus we have not investigated the temperaturedependency in this study. However, as the studied temperature is at the higher end of typical atmospheric range and cluster evaporation strongly decreases with decreasing temperature, the results can be considered as lower-limit estimates for cluster concentrations and NPF rates. Finally, the molecular collision rates (eq 7) may be enhanced by electrostatic forces due to dipoles within the strongly ionic cluster structures, which could also lead to even stronger cluster formation. Overall, our results suggest that highly basic amines such as guanidine can explain NPF rates at low sulfuric acid concentrations, whereas more abundant and less basic species can produce observed NPF rates at higher concentrations. These conclusions are in good agreement with recent studies of sulfuric acid-base clusters. ${ }^{22,24,92}$

\section{CONCLUSIONS}

The potential role of guanidine in sulfuric acid-driven newparticle formation in the atmosphere was explored. We used state-of-the-art quantum chemical methods to study structures and thermodynamics up to the cluster size of four guanidine and four sulfuric acid molecules. We found the molecular interaction between guanidine and sulfuric acid to be extremely strong, which is due to the proton transfer from sulfuric acid to guanidine and thus the formation of a symmetric, resonance stabilized, and Y-aromatic guanidinium ion. The cluster growth occurs through compositions close to a 1:1 ratio of sulfuric acid 
and guanidine, as these clusters $(n \mathrm{G} n \mathrm{~A}$ and $(n \pm 1) \mathrm{G} n \mathrm{~A})$ are found to be very stable against evaporation. Our theoretical findings were further confirmed by ESI-APi-TOF measurements.

We showed that guanidine forms clusters with sulfuric acid much more efficiently than dimethylamine, which is a relatively strong atmospheric cluster stabilizer compared to more abundant species such as ammonia. For dimethylamine to reach the same enhancing effect on cluster formation as guanidine, more than a 2000 -fold concentration is required. Our results show that even at very low concentration, guanidine is capable of participating in the initial steps of new-particle formation as a highly efficient stabilizing species, even at warmer temperatures where weaker stabilizers become less efficient. Therefore, we suggest that very strong bases such as guanidine may have an important role in forming the smallest stable clusters. After the formation of small guanidine-sulfuric acid clusters, cluster growth may occur by uptake of more abundant and less basic bases (e.g., ammonia and some amines). Particle formation and growth to larger sizes might also be assisted by highly oxidized multifunctional compounds (HOMs). ${ }^{5}$ Experimental findings have showed that HOMs can participate in the new-particle formation; however, our theoretical results have indicated that sulfuric acid and HOMs even together with common stabilizing species (e.g., bisulfate, ammonia, ammonium, dimethylamine, water) cannot form stable clusters at atmospheric conditions. ${ }^{66,78,93-95}$ Therefore, our findings might make an important contribution for solving the role of HOMs in the atmospheric new-particle formation.

To conclude, quantifying the role of guanidine with respect to other basic species requires constraining its atmospheric concentrations. As even very low mixing ratios of guanidine are likely to result in efficient cluster formation, potentially triggering notable local-scale particle formation events, detection of also only trace levels is important. While such measurements can be challenging, they may be essential for resolving otherwise inexplicable particle formation phenomena. Therefore, we hope that our work will inspire field measurements for assessing the abundance of gas-phase guanidine in different environments.

\section{ASSOCIATED CONTENT}

\section{S Supporting Information}

The Supporting Information is available free of charge on the ACS Publications website at DOI: 10.1021/acs.jpca.8b02507.

The $x y z$ structures for guanidine-sulfuric acid clusters (ZIP)

Benchmark results for DLPNO-CCSD(T) method with different basis sets; thermal contributions to the Gibbs free energies (DFT/6-31++ $\left.\mathrm{G}^{* *}\right)$, electronic energy corrections (DLPNO-CCSD $(\mathrm{T}) /$ aug-cc-pVTZ), average Gibbs free energies, and Gibbs free binding energies (DLPNO//DFT) for guanidine-sulfuric acid clusters; actual Gibbs free energies and main growth pathways for guanidine-sulfuric acid clusters at guanidine concentrations of $10^{-3}$ and $10^{-6} \mathrm{ppt}_{V}$; ratios of monomer collision and evaporation frequencies; negatively charged guanidine-ammonia-sulfuric acid clusters observed by APi-TOF; Gibbs free binding energies, actual Gibbs free energies, and total evaporation rates for guanidinesulfuric acid and dimethylamine-sulfuric acid clusters (DLPNO-CCSD (T)/aug-cc-pVTZ// $\omega$ B97X-D/6-31+
$\left.+\mathrm{G}^{* *}\right)$; dimethylamine-sulfuric acid cluster distribution at dimethylamine concentration of $2200 \mathrm{ppt}_{V}(\mathrm{PDF})$

\section{AUTHOR INFORMATION}

\section{Corresponding Authors}

*N.M.: e-mail, nanna.myllys@helsinki.fi; phone, +358 503812141.

*T.O.: e-mail, tinja.olenius@alumni.helsinki.fi, phone, +46 86747282.

ORCID $\odot$

Nanna Myllys: 0000-0003-0384-7277

Jonas Elm: 0000-0003-3736-4329

\section{Notes}

The authors declare no competing financial interest.

\section{ACKNOWLEDGMENTS}

We thank the Academy of Finland, ERC Project 692891DAMOCLES, ATMATH Project, Swedish Research Council Formas Project 2015-749, and Knut and Alice Wallenberg Foundation (Academy Fellowship AtmoRemove) for funding, and the CSC-IT Center for Science in Espoo, Finland, for computational resources. J.E. thanks the Villum Foundation for financial support.

\section{REFERENCES}

(1) Zhang, R.; Khalizov, A.; Wang, L.; Hu, M.; Xu, W. Nucleation and Growth of Nanoparticles in the Atmosphere. Chem. Rev. 2012, 112, 1957-2011.

(2) Hallquist, M.; Wenger, J. C.; Baltensperger, U.; Rudich, Y.; Simpson, D.; Claeys, M.; Dommen, J.; Donahue, N. M.; George, C.; Goldstein, A. H.; et al. The Formation, Properties and Impact of Secondary Organic Aerosol: Current and Emerging Issues. Atmos. Chem. Phys. 2009, 9, 5155-5236.

(3) Kulmala, M.; Riipinen, I.; Sipilä, M.; Manninen, H. E.; Petäjä, T.; Junninen, H.; Maso, M. D.; Mordas, G.; Mirme, A.; Vana, M.; et al. Toward Direct Measurement of Atmospheric Nucleation. Science 2007, 318, 89-92.

(4) Kulmala, M.; Kontkanen, J.; Junninen, H.; Lehtipalo, K.; Manninen, H. E.; Nieminen, T.; Petäjä, T.; Sipilä, M.; Schobesberger, S.; Rantala, P.; et al. Direct Observations of Atmospheric Aerosol Nucleation. Science 2013, 339, 943-946.

(5) Ehn, M.; Thornton, J. A.; Kleist, E.; Sipilae, M.; Junninen, H.; Pullinen, I.; Springer, M.; Rubach, F.; Tillmann, R.; Lee, B.; et al. A Large Source of Low-Volatility Secondary Organic Aerosol. Nature 2014, 506, 476-479.

(6) Riccobono, F.; Schobesberger, S.; Scott, C. E.; Dommen, J.; Ortega, I. K.; Rondo, L.; Almeida, J.; Amorim, A.; Bianchi, F.; Breitenlechner, M.; et al. Oxidation Products of Biogenic Emissions Contribute to Nucleation of Atmospheric Particles. Science 2014, 344, 717-721.

(7) Schobesberger, S.; Junninen, H.; Bianchi, F.; Lönn, G.; Ehn, M.; Lehtipalo, K.; Dommen, J.; Ehrhart, S.; Ortega, I. K.; Franchin, A.; et al. Molecular Understanding of Atmospheric Particle Formation from Sulfuric Acid and Large Oxidized Organic Molecules. Proc. Natl. Acad. Sci. U. S. A. 2013, 110, 17223-17228.

(8) Kirkby, J.; Duplissy, J.; Sengupta, K.; Frege, C.; Gordon, H.; Williamson, C.; Heinritzi, M.; Simon, M.; Yan, C.; Almeida, J.; et al. Ion-Induced Nucleation of Pure Biogenic Particles. Nature 2016, 533, $521-526$

(9) Xu, Y.; Nadykto, A. B.; Yu, F.; Herb, J.; Wang, W. Interaction between Common Organic Acids and Trace Nucleation Species in the Earth's Atmosphere. J. Phys. Chem. A 2010, 114, 387-396.

(10) Xu, Y.; Nadykto, A. B.; Yu, F.; Jiang, L.; Wang, W. Formation and Properties of Hydrogen-Bonded Complexes of Common Organic 
Oxalic Acid with Atmospheric Nucleation Precursors. J. Mol. Struct.: THEOCHEM 2010, 951, 28-33.

(11) Nadykto, A. B.; Yu, F. Strong Hydrogen Bonding between Atmospheric Nucleation Precursors and Common Organics. Chem. Phys. Lett. 2007, 435, 14-18.

(12) Temelso, B.; Morrison, E. F.; Speer, D. L.; Cao, B. C.; AppiahPadi, N.; Kim, G.; Shields, G. C. Effect of Mixing Ammonia and Alkylamines on Sulfate Aerosol Formation. J. Phys. Chem. A 2018, 122, 1612-1622.

(13) Anderson, N.; Strader, R.; Davidson, C. Airborne Reduced Nitrogen: Ammonia Emissions from Agriculture and Other Sources. Environ. Int. 2003, 29, 277-286.

(14) Kurtén, T.; Torpo, L.; Ding, C.-G.; Vehkamäki, H.; Sundberg, M. R.; Laasonen, K.; Kulmala, M. A Density Functional Study on Water-Sulfuric Acid-Ammonia Clusters and Implications for Atmospheric Cluster Formation. J. Geophys. Res. 2007, 112, D04210.

(15) Ge, X.; Wexler, A. S.; Clegg, S. L. Atmospheric Amines - Part I. A Review. Atmos. Environ. 2011, 45, 524-546.

(16) Ho, K.-L.; Chung, Y.-C.; Lin, Y.-H.; Tseng, C.-P. Biofiltration of Trimethylamine, Dimethylamine, and Methylamine by Immobilized Paracoccus sp. CP2 and Arthrobacter sp. CP1. Chemosphere 2008, 72, 250-256.

(17) Loukonen, V.; Kurtén, T.; Ortega, I. K.; Vehkamäki, H.; Pádua, A. A. H.; Sellegri, K.; Kulmala, M. Enhancing Effect of Dimethylamine in Sulfuric Acid Nucleation in the Presence of Water - A Computational Study. Atmos. Chem. Phys. 2010, 10, 4961-4974.

(18) Olenius, T.; Kupiainen-Määttä, O.; Ortega, I. K.; Kurtén, T.; Vehkamäki, H. Free Energy Barrier in the Growth of Sulfuric AcidAmmonia and Sulfuric Acid-Dimethylamine Clusters. J. Chem. Phys. 2013, 139, 084312.

(19) Kurtén, T.; Loukonen, V.; Vehkamäki, H.; Kulmala, M. Amines Are Likely to Enhance Neutral and Ion-Induced Sulfuric Acid-Water Nucleation in the Atmosphere More Effectively Than Ammonia. Atmos. Chem. Phys. 2008, 8, 4095-4103.

(20) Almeida, J.; Schobesberger, S.; Kürten, A.; Ortega, I. K.; Kupiainen-Määttä, O.; Praplan, A. P.; Adamov, A.; Amorim, A.; Bianchi, F.; Breitenlechner, M.; et al. Molecular Understanding of Sulphuric Acid-Amine Particle Nucleation in the Atmosphere. Nature 2013, 502, 359-363.

(21) Xie, H.-B.; Elm, J.; Halonen, R.; Myllys, N.; Kurtén, T.; Kulmala, M.; Vehkamäki, H. Atmospheric Fate of Monoethanolamine: Enhancing New Particle Formation of Sulfuric Acid as an Important Removal Process. Environ. Sci. Technol. 2017, 51, 8422-8431.

(22) Elm, J.; Jen, C. N.; Kurtén, T.; Vehkamäki, H. Strong Hydrogen Bonded Molecular Interactions between Atmospheric Diamines and Sulfuric Acid. J. Phys. Chem. A 2016, 120, 3693-3700.

(23) Jen, C. N.; Bachman, R.; Zhao, J.; McMurry, P. H.; Hanson, D. R. Diamine-Sulfuric Acid Reactions Are a Potent Source of New Particle Formation. Geophys. Res. Lett. 2016, 43, 867-873.

(24) Elm, J.; Passananti, M.; Kurtén, T.; Vehkämaki, H. Diamines Can Initiate New Particle Formation in the Atmosphere. J. Phys. Chem. A 2017, 121, 6155-6164.

(25) Wang, C.-Y.; Jiang, S.; Liu, Y.-R.; Wen, H.; Wang, Z.-Q.; Han, Y.-J.; Huang, T.; Huang, W. Synergistic Effect of Ammonia and Methylamine on Nucleation in the Earth's Atmosphere. A Theoretical Study. J. Phys. Chem. A 2018, 122, 3470-3479.

(26) Glasoe, W.; Volz, K.; Panta, B.; Freshour, N.; Bachman, R; Hanson, D.; McMurry, P.; Jen, C. Sulfuric Acid Nucleation: An Experimental Study of the Effect of Seven Bases. J. Geophys. Res. Atmos. 2015, 120, 1933-1950.

(27) Yu, H.; McGraw, R.; Lee, S.-H. Effects of amines on formation of sub-3 nm particles and their subsequent growth. Geophys. Res. Lett. 2012, 39, DOI: 10.1029/2011GL050099.

(28) Angyal, S. J.; Warburton, W. K. The Basic Strengths of Methylated Guanidines. J. Chem. Soc. 1951, 549, 2492-2494.

(29) Gund, P. Guanidine, Trimethylenemethane, and "Y-Delocalization." Can Acyclic Compounds Have "Aromatic" Stability? J. Chem. Educ. 1972, 49, 100.
(30) Marcus, Y. The Guanidinium Ion. J. Chem. Thermodyn. 2012, $48,70-74$.

(31) Raczyńska, E. D.; Cyrański, M. K.; Gutowski, M.; Rak, J.; Gal, J.F.; Maria, P.-C.; Darowska, M.; Duczmal, K. Consequences of Proton Transfer in Guanidine. J. Phys. Org. Chem. 2003, 16, 91-106.

(32) Kumar, R.; Choudhary, V.; Mishra, S.; Varma, I.; Mattiason, B. Adhesives and Plastics Based on Soy Protein Products. Ind. Crops Prod. 2002, 16, 155-172.

(33) Oxley, J. C.; Smith, J. L.; Naik, S.; Moran, J. Decompositions of Urea and Guanidine Nitrates. J. Energ. Mater. 2008, 27, 17-39.

(34) Zhao, Z.; Dai, Y.; Ge, G.; Wang, G. Guanidine Nitrate Enhanced Catalysis of Nitrogen-Doped Carbon Nanotubes for Metal-Free Styrene Production through Direct Dehydrogenation. ChemCatChem 2015, 7, 1135-1144.

(35) Marescau, B.; Deshmukh, D. R.; Kockx, M.; Possemiers, I.; Qureshi, I. A.; Wiechert, P.; De Deyn, P. P. Guanidino Compounds in Serum, Urine, Liver, Kidney, and Brain of Man and Some Ureotelic Animals. Metab., Clin. Exp. 1992, 41, 526-532.

(36) Bonas, J. E.; Cohen, B. D.; Natelson, S. Separation and Estimation of Certain Guanidino Compounds. Application to Human Urine. Microchem. J. 1963, 7, 63-77.

(37) Ishikawa, T. Guanidine Chemistry. Chem. Pharm. Bull. 2010, 58, $1555-1564$.

(38) Wei, D.; Ma, Q.; Guan, Y.; Hu, F.; Zheng, A.; Zhang, X.; Teng, Z.; Jiang, H. Structural Characterization and Antibacterial Activity of Oligoguanidine (Polyhexamethylene Guanidine Hydrochloride). Mater. Sci. Eng., C 2009, 29, 1776-1780.

(39) Yeagley, A. A.; Su, Z.; McCullough, K. D.; Worthington, R. J.; Melander, C. N-Substituted 2-Aminoimidazole Inhibitors of MRSA Biofilm Formation Accessed Through Direct 1,3-Bis(TertButoxycarbonyl)Guanidine Cyclization. Org. Biomol. Chem. 2013, 11, 130-137.

(40) Van Pilsum, J. F.; Martin, R. P.; Kito, E.; Hess, J. Determination of Creatine, Creatinine, Arginine, Guanidinoacetic Acid, Guanidine, and Methylguanidine in Biological Fluids. J. Biol. Chem. 1956, 222, 225-236.

(41) Swick, R. W. Measurement of Protein Turnover in Rat Liver. J. Biol. Chem. 1958, 231, 751-764.

(42) McGrath, M. J.; Olenius, T.; Ortega, I. K.; Loukonen, V.; Paasonen, P.; Kurtén, T.; Kulmala, M.; Vehkamäki, H. Atmospheric Cluster Dynamics Code: a Flexible Method for Solution of the BirthDeath Equations. Atmos. Chem. Phys. 2012, 12, 2345-2355.

(43) Frisch, M. J.; Trucks, G. W.; Schlegel, H. B.; Scuseria, G. E.; Robb, M. A.; Cheeseman, J. R.; Scalmani, G.; Barone, V.; Petersson, G. A.; Nakatsuji, H.; et al.. Gaussian 16, revision A.03; Gaussian, Inc.: Wallingford, CT, 2016.

(44) Neese, F. The ORCA Program System. Wiley Interdiscip. Rev. Comput. Mol. Sci. 2012, 2, 73-78.

(45) Elm, J.; Bilde, M.; Mikkelsen, K. V. Influence of Nucleation Precursors on the Reaction Kinetics of Methanol with the OH Radical. J. Phys. Chem. A 2013, 117, 6695-6701.

(46) Stewart, J. J. Optimization of Parameters for Semiempirical Methods V: Modification of NDDO Approximations and Application to 70 Elements. J. Mol. Model. 2007, 13, 1173-1213.

(47) Zhao, Y.; Truhlar, D. G. The M06 Suite of Density Functionals for Main Group Thermochemistry, Thermochemical Kinetics, Noncovalent Interactions, Excited States, and Transition Elements: Two New Functionals and Systematic Testing of Four M06-Class Functionals and 12 Other Functionals. Theor. Chem. Acc. 2008, 120, $215-241$.

(48) Perdew, J. P.; Wang, Y. Accurate and Simple Analytic Representation of the Electron-Gas Correlation Energy. Phys. Rev. B: Condens. Matter Mater. Phys. 1992, 45, 13244-13249.

(49) Chai, J.-D.; Head-Gordon, M. Long-Range Corrected Hybrid Density Functionals with Damped Atom-Atom Dispersion Corrections. Phys. Chem. Chem. Phys. 2008, 10, 6615-6620.

(50) Krishnan, R.; Binkley, J. S.; Seeger, R.; Pople, J. A. SelfConsistent Molecular Orbital Methods. XX. A Basis Set for Correlated Wave Functions. J. Chem. Phys. 1980, 72, 650-654. 
(51) Hehre, W. J.; Ditchfield, R.; Pople, J. A. Self-Consistent Molecular Orbital Methods. XII. Further Extensions of Gaussian-Type Basis Sets for Use in Molecular Orbital Studies of Organic Molecules. J. Chem. Phys. 1972, 56, 2257-2261.

(52) Frisch, M. J.; Pople, J. A.; Binkley, J. S. Self-Consistent Molecular Orbital Methods 25. Supplementary Functions for Gaussian Basis Sets. J. Chem. Phys. 1984, 80, 3265-3269.

(53) Elm, J.; Bilde, M.; Mikkelsen, K. V. Assessment of Density Functional Theory in Predicting Structures and Free Energies of Reaction of Atmospheric Prenucleation Clusters. J. Chem. Theory Comput. 2012, 8, 2071-2077.

(54) Ding, C.-G.; Laasonen, K.; Laaksonen, A. Two Sulfuric Acids in Small Water Clusters. J. Phys. Chem. A 2003, 107, 8648-8658.

(55) Leverentz, H. R.; Siepmann, J. I.; Truhlar, D. G.; Loukonen, V.; Vehkamäki, H. Energetics of Atmospherically Implicated Clusters Made of Sulfuric Acid, Ammonia, and Dimethyl Amine. J. Phys. Chem. A 2013, 117, 3819-3825.

(56) Elm, J.; Mikkelsen, K. V. Computational Approaches for Efficiently Modelling of Small Atmospheric Clusters. Chem. Phys. Lett. 2014, 615, 26-29.

(57) Myllys, N.; Elm, J.; Kurtén, T. Density Functional Theory Basis Set Convergence of Sulfuric Acid-Containing Molecular Clusters. Comput. Theor. Chem. 2016, 1098, 1-12.

(58) Elm, J.; Myllys, N.; Hyttinen, N.; Kurtén, T. Computational Study of the Clustering of a Cyclohexene Autoxidation Product $\mathrm{C}_{6} \mathrm{H}_{8} \mathrm{O}_{7}$ with Itself and Sulfuric Acid. J. Phys. Chem. A 2015, 119, 8414-8421.

(59) Riplinger, C.; Neese, F. An Efficient and Near Linear Scaling Pair Natural Orbital Based Local Coupled Cluster Method. J. Chem. Phys. 2013, 138, 034106.

(60) Riplinger, C.; Sandhoefer, B.; Hansen, A.; Neese, F. Natural Triple Excitations in Local Coupled Cluster Calculations with Pair Natural Orbitals. J. Chem. Phys. 2013, 139, 134101.

(61) Riplinger, C.; Pinski, P.; Becker, U.; Valeev, E. F.; Neese, F. Sparse Maps-A Systematic Infrastructure for Reduced-Scaling Electronic Structure Methods. II. Linear Scaling Domain Based Pair Natural Orbital Coupled Cluster Theory. J. Chem. Phys. 2016, 144, 024109.

(62) Dunning, T. H. Gaussian Basis Sets for Use in Correlated Molecular Calculations. I. The Atoms Boron Through Neon and Hydrogen. J. Chem. Phys. 1989, 90, 1007-1023.

(63) Kendall, R. A.; Dunning, T. H.; Harrison, R. J. Electron Affinities of the First-Row Atoms Revisited. Systematic Basis Sets and Wave Functions. J. Chem. Phys. 1992, 96, 6796-6806.

(64) Liakos, D. G.; Sparta, M.; Kesharwani, M. K.; Martin, J. M. L.; Neese, F. Exploring the Accuracy Limits of Local Pair Natural Orbital Coupled-Cluster Theory. J. Chem. Theory Comput. 2015, 11, 15251539.

(65) Myllys, N.; Elm, J.; Halonen, R.; Kurtén, T.; Vehkamäki, H. Coupled Cluster Evaluation of the Stability of Atmospheric Acid-Base Clusters with up to 10 Molecules. J. Phys. Chem. A 2016, 120, 621630.

(66) Myllys, N.; Olenius, T.; Kurtén, T.; Vehkamäki, H.; Riipinen, I.; Elm, J. Effect of Bisulfate, Ammonia, and Ammonium on the Clustering of Organic Acids and Sulfuric Acid. J. Phys. Chem. A 2017, 121, 4812-4824.

(67) Elm, J.; Kristensen, K. Basis Set Convergence of the Binding Energies of Strongly Hydrogen-Bonded Atmospheric Clusters. Phys. Chem. Chem. Phys. 2017, 19, 1122-1133.

(68) Kupiainen-Määttä, O.; Olenius, T.; Kurtén, T.; Vehkamäki, H. CIMS Sulfuric Acid Detection Efficiency Enhanced by Amines Due to Higher Dipole Moments: A Computational Study. J. Phys. Chem. A 2013, 117, 14109-14119.

(69) Ortega, I. K.; Kupiainen, O.; Kurtén, T.; Olenius, T.; Wilkman, O.; McGrath, M. J.; Loukonen, V.; Vehkamäki, H. From Quantum Chemical Formation Free Energies to Evaporation Rates. Atmos. Chem. Phys. 2012, 12, 225-235.

(70) Chapman, S.; Cowling, T. G. The Mathematical Theory of NonUniform Gases; University Press: Cambridge, U.K., 1970.
(71) Shampine, L.; Reichelt, M. The MATLAB ODE Suite. SIAM J. Sci. Comput. 1997, 18, 1-22.

(72) Lehtinen, K. E.; Dal Maso, M.; Kulmala, M.; Kerminen, V.-M. Estimating Nucleation Rates from Apparent Particle Formation Rates and Vice Versa: Revised Formulation of the Kerminen-Kulmala Equation. J. Aerosol Sci. 2007, 38, 988-994.

(73) Junninen, H.; Ehn, M.; Petäjä, T.; Luosujärvi, L.; Kotiaho, T.; Kostiainen, R.; Rohner, U.; Gonin, M.; Fuhrer, K.; Kulmala, M.; et al. A High-Resolution Mass Spectrometer to Measure Atmospheric Ion Composition. Atmos. Meas. Tech. 2010, 3, 1039-1053.

(74) Valeev, E. F. Coupled-Cluster Methods with Perturbative Inclusion of Explicitly Correlated Terms: a Preliminary Investigation. Phys. Chem. Chem. Phys. 2008, 10, 106-113.

(75) Olenius, T.; Halonen, R.; Kurtén, T.; Henschel, H.; KupiainenMäättä, O.; Ortega, I. K.; Jen, C. N.; Vehkamäki, H.; Riipinen, I. New Particle Formation from Sulfuric Acid and Amines: Comparison of Mono-, Di-, and Trimethylamines. J. Geophys. Res. Atmos. 2017, 122, $7103-7118$.

(76) Kupiainen, O.; Ortega, I. K.; Kurtén, T.; Vehkamäki, H. Amine Substitution into Sulfuric Acid-Ammonia Clusters. Atmos. Chem. Phys. 2012, 12, 3591-3599.

(77) Ortega, I. K.; Kurtén, T.; Vehkamäki, H.; Kulmala, M. The Role of Ammonia in Sulfuric Acid Ion Induced Nucleation. Atmos. Chem. Phys. 2008, 8, 2859-2867.

(78) Myllys, N. From Electronic Structures to Molecular-Level Cluster Formation Mechanisms in the Atmosphere. Ph.D. Thesis, University of Helsinki, Finland, 2017.

(79) Chéron, N.; Jacquemin, D.; Fleurat-Lessard, P. A Qualitative Failure of B3LYP for Textbook Organic Reactions. Phys. Chem. Chem. Phys. 2012, 14, 7170-7175.

(80) Montgomery, J. A., Jr; Frisch, M. J.; Ochterski, J. W.; Petersson, G. A. A Complete Basis Set Model Chemistry. VI. Use of Density Functional Geometries and Frequencies. J. Chem. Phys. 1999, 110, $2822-2827$.

(81) Hättig, C.; Weigend, F. CC2 Excitation Energy Calculations on Large Molecules Using the Resolution of the Identity Approximation. J. Chem. Phys. 2000, 113, 5154-5161.

(82) Christiansen, O.; Koch, H.; Jørgensen, P. The Second-Order Approximate Coupled Cluster Singles and Doubles Model CC2. Chem. Phys. Lett. 1995, 243, 409-418.

(83) Pabst, M.; Köhn, A.; Gauss, J.; Stanton, J. F. A Worrisome Failure of the CC2 Coupled-Cluster Method When Applied to Ozone. Chem. Phys. Lett. 2010, 495, 135-140.

(84) Nadykto, A. B.; Herb, J.; Yu, F.; Xu, Y. Enhancement in the Production of Nucleating Clusters due to Dimethylamine and Large Uncertainties in the Thermochemistry of Amine-Enhanced Nucleation. Chem. Phys. Lett. 2014, 609, 42-49.

(85) Nadykto, A. B.; Herb, J.; Yu, F.; Nazarenko, E. S.; Xu, Y. Reply to the 'Comment on "Enhancement in the Production of Nucleating Clusters due to Dimethylamine and Large Uncertainties in the Thermochemistry of Amine-Enhanced Nucleation"' by KupiainenMaatta et al. Chem. Phys. Lett. 2015, 624, 111-118.

(86) Hättig, C. Geometry Optimizations With the Coupled-Cluster Model CC2 Using the Resolution-of-the-Identity Approximation. J. Chem. Phys. 2003, 118, 7751-7761.

(87) Bianchi, F.; Praplan, A. P.; Sarnela, N.; Dommen, J.; Kürten, A.; Ortega, I. K.; Schobesberger, S.; Junninen, H.; Simon, M.; Tröstl, J.; et al. Insight into Acid-Base Nucleation Experiments by Comparison of the Chemical Composition of Positive, Negative, and Neutral Clusters. Environ. Sci. Technol. 2014, 48, 13675-13684.

(88) Ortega, I. K.; Olenius, T.; Kupiainen-Määttä, O.; Loukonen, V.; Kurtén, T.; Vehkamäki, H. Electrical Charging Changes the Composition of Sulfuric Acid-Ammonia/Dimethylamine Clusters. Atmos. Chem. Phys. 2014, 14, 7995-8007.

(89) Elm, J. Elucidating the Limiting Steps in Sulfuric Acid-Base New Particle Formation. J. Phys. Chem. A 2017, 121, 8288-8295.

(90) Jen, C. N.; McMurry, P. H.; Hanson, D. R. Stabilization of Sulfuric Acid Dimers by Ammonia, Methylamine, Dimethylamine, and Trimethylamine. J. Geophys. Res. Atmos. 2014, 119, 7502-7514. 
(91) Kürten, A.; Bergen, A.; Heinritzi, M.; Leiminger, M.; Lorenz, V.; Piel, F.; Simon, M.; Sitals, R.; Wagner, A. C.; Curtius, J. Observation of New Particle Formation and Measurement of Sulfuric Acid, Ammonia, Amines and Highly Oxidized Organic Molecules at a Rural Site in Central Germany. Atmos. Chem. Phys. 2016, 16, 12793-12813.

(92) Bzdek, B. R.; DePalma, J. W.; Johnston, M. V. Mechanisms of Atmospherically Relevant Cluster Growth. Acc. Chem. Res. 2017, 50, 1965-1975.

(93) Elm, J.; Myllys, N.; Luy, J.-N.; Kurtén, T.; Vehkamäki, H. The Effect of Water and Bases on the Clustering of a Cyclohexene Autoxidation Product $\mathrm{C}_{6} \mathrm{H}_{8} \mathrm{O}_{7}$ with Sulfuric Acid. J. Phys. Chem. A 2016, 120, 2240-2249.

(94) Elm, J.; Myllys, N.; Olenius, T.; Halonen, R.; Kurtén, T.; Vehkämaki, H. Formation of Atmospheric Molecular Clusters Consisting of Sulfuric Acid and $\mathrm{C}_{8} \mathrm{H}_{12} \mathrm{O}_{6}$ Tricarboxylic Acid. Phys. Chem. Chem. Phys. 2017, 19, 4877-4886.

(95) Elm, J.; Myllys, N.; Kurtén, T. What Is Required for Highly Oxidized Molecules To Form Clusters with Sulfuric Acid? J. Phys. Chem. A 2017, 121, 4578-4587. 